\title{
NATURALEZA DE LA FUNCION DE LAS ASAMBLEAS LEGISLATIVAS DE LAS COMUNIDADES AUTONOMAS: ALGUNAS CONSECUENCIAS CRITICAS ( $\left.{ }^{*}\right)$
}

por

\author{
José Luis Martínez López-Muñiz \\ Profesor Titular de Derecho Administrativo \\ de la Universidad de Valladolid.
}

SUMARIO: I. INTRODUCCION: SEMANTICA DE LA AUTONOMIA POLITICA.-II. DETERMINACION ESTATUTARIA DE LA FUNCION DE LOS PARLAMENTOS AUTONOMICOS.III. UNA POTESTAD LEGISLATIVA FORMAL, PERO SUBORDINADA. - IV. AMBITO OBJETIVO DE LAS LEYES AUTONOMICAS (MATERIAS Y NIVELES DE REGULACION).-V. NATURALEZA DE LA POTESTAD LEGISLATIVA AUTONOMICA.-VI. OBSERVACIONES SOBRE LA POTESTAD REGLAMENTARIA DE LAS COMUNIDADES AUTONOMAS.VII. ALGUNAS REFERENCIAS DE DERECHO COMPARADO: ITALIA, BELGICA Y ALEMANIA.-VIII. REFLEXIONES CRITICAS FINALES SOBRE LAS CONSECUENCIAS ESTRUCTURALES Y FUNCIONALES DE LA CARACTERIZACION FORMALMENTE LEGISLATIVA DE LAS ASAMBLEAS AUTONOMICAS POR RAZON DE SUS FUNCIONES.

$\left({ }^{*}\right)$ Comunicación presentada en "Jornadas de Estudio sobre las Cortes Generales", Valladolid. Madrid, 21 mayo 1985. Ministerio de Justicia. Cuerpo Superior de Letrados del Estado. 


\section{INTRODUCCION:}

\section{SEMANTICA DE LA AUTONOMIA POLITICA}

La génesis y configuración de las Comunidades Autónomas, sobre la base del principio constitucional del derecho a la autonomía de las Nacionalidades y Regiones que integran la unidad de la Nación española (art. $2 .^{\circ} \mathrm{CE}$ ), y conforme al patrón que, apuntado para algunos supuestos en el Título VIII de la Constitución, se generaliza a través de los Estatutos de Autonomía, resulta esencialmente deudora de un extendido estado de opinión política y jurídica que reclamaba para las Regiones - simpliciter o "nacionalitarias»- una autonomía politica y no meramente administrativa y que cifraba, no sin simplificación, la diferencia entre una y otra en que aquélla habría de implicar necesariamente una autonomía legislativa, además de una autonomía administrativa (1).

Contraponer, sin más, lo político a lo administrativo, remitiendo lo primero por añadidura solamente a lo legislativo, representa desconocer que, como se ha dicho, lo administrativo está siempre «transido de politicidad» y que las Administraciones públicas pueden tener, y de hecho tienen habitualmente, facultades normativas y decisorias de extensa e intensa relevancia política, sin perjuicio de su naturaleza subordinada o de su deber de servir con objetividad los intereses generales - por decirlo con palabras del art. 103 de nuestra Constitucióncon sometimiento pleno a la Ley y al Derecho.

Es verdad que, convencionalmente, puede hablarse de lo político para referirse a las decisiones y normas superiores y más importantes de una comunidad que, de ordinario, se expresan en los Estados actuales en forma legislativa, mientras que lo administrativo pertenece precisamente al orden de lo subordinado y secundario. Pero no es menos cierto que estas calificaciones tienen una significación inevitablemente relativa, lo que explica, por ejemplo, que sea dificil negar una actividad política a las Corporaciones locales, a pesar de su naturaleza propiamente administrativa.

Por otra parte, no puede desconocerse que la mera formalización de una potestad, de unas competencias, de unas actividades o de unos órganos como legislativos, aunque tenga siempre algunas consecuencias, puede venir a ser un superficial revestimiento nominal que no

(1) Una critica a tal modo de simplificar la distinción en PALADIN, L.: La potestá legislativa regionale, Padova, 1958, p. 260 y ss., y Diritto regionale, CEDAM. Padova. 1973, pp. 32-33. 
implique la amplitud de decisión política que, en principio, sugiere la presencia de lo legislativo. Georges BURDEAU ha observado, en este sentido, en relación con el estatuto propio de las Regiones de nuestra II República, que en él on ne perçoit une chance offerte $\grave{a}$ l'expression d'un Pouvoir proprement politique, c'est-à-dire libre de ses propres déterminations, y que, qualitativement, ses compétences, même législatives, ne lui permettent pas - a la Región-d'exprimer une volonté primaire et inconditionnée (2).

Doctrinalmente se han sostenido, además, muy variadas posiciones acerca del concepto de lo legislativo (3). Y autores como DUGUIT, reaccionando contra un concepto formal de la Ley, han sostenido que, junto a la ley nacional, existen leyes regionales y locales, leyes de grupos (4), y que «hoy, de hecho y de derecho, los Municipios, al menos las grandes ciudades, tienen incontestablemente una legislación propia, completamente distinta de la ley nacional», siendo los reglamentos municipales "verdaderas leyes» (5).

Situar, en fin, el límite entre lo político y lo administrativo, y aun entre la verdadera autonomía y la simple descentralización administrativa - como se ha hecho-, en el reconocimiento o no, en favor de las comunidades organizadas de que se trate, de un indefinido poder legislativo, resulta de más que discutible rigor.

Pero tal criterio ha sido, sin duda, determinante en la conformación de nuestro Estado de las Autonomías, aunque la necesidad de salvaguardar los principios de unidad y solidaridad, proclamados destacadamente en el artículo $2 .^{\circ}$ de la Constitución, dentro del sistema de libertades, esencial a nuestro orden constitucional, haya obligado a configurar la potestad legislativa autonómica de un modo que difícilmente resistirá valoraciones críticas como las

(2) Cfr. Burdeau. G.: Traité de science politique, II, 2.a ed., LGDJ, Paris, 1967, p. 388. Refiriendose al poder de las Regiones italianas dirá tambièn que ne doit cette qualification $q u ' a$ une vision embellisante et toute méridionale de la réalité (op. cit., p. 391, donde habla de la potestad "legislativa" de dichas Regiones).

(3) Vid. CARRE DE MALBERG, R.: La Loi, expression de la voloniégénérale, préface de G. Burdeau. Economica, Paris, 1984: STARCK, Christian: El concepto de ley en la Constitución alemana, tr. esp. y prólogo de L. Legaz Lacambra, CEC, Madrid, 1979; GALLEGO ANABITARTE, A.: Ley y reglamento en el Derecho público occidental, IEA, Madrid, 1971: JESCH, D.: Ley y Administración, IEA, Madrid, 1978: GARRORENA MORALES, A.: El lugar de la Ley en la Constitución española, CEC, Madrid, 1980.

(4) Cfr. Duguit, L.: Las transformaciones del Derecho público, tr. con estudio preliminar de A. Posada y R. Jaen, 2.a ed., Ed. F. Beltrán, Madrid, 1926, p. 166 y ss.

(5) Cfr. Duguit, L.: op. cit., supra, pp. 170 y 171. 
que un BURDEAU dedicara al precedente de la función legiferante de las Regiones de la II República.

La preocupación por organizar las Comunidades Autónomas a tono con la titularidad del alto cometido de legislar y con su proclamada autonomía política, lanzaría al legislador estatuyente por los caminos del mimetismo estatal, promoviendo unas estructuras inspiradas en el principio de separación de poderes y en la forma parlamentaria de gobierno, así como un esquema funcional determinante de Administraciones de corte burocrático, alejado del modelo de las Administraciones corporativas territoriales y de la autoadministración (6), por el que podría, en cambio, haberse optado, con las necesarias adaptaciones, sin merma de una real autonomía política y con evidente provecho para una más plena y efectiva realización del principio de participación política y administrativa, al que la doctrina suele, por otra parte, vincular aquélla.

Mas es claro que el proceso de conformación del Estado de las Autonomías y de las distintas Comunidades Autónomas, no puede considerarse definitivamente cerrado, ni irreversiblemente ya orientado. Sin necesidad de recalar en el tan traído y llevado tema de la reforma del Título VIII de la Constitución, que no creo imprescindible, puede perfectamente afirmarse la posibilidad de reorientar la definitiva ordenación de las Comunidades Autónomas, con la profundidad e intensidad que sea conveniente, a la luz, precisamente, de la experiencia que su funcionamiento práctico va proporcionando. No en vano, en el espíritu de la Constitución está la idea de una primera etapa de implantación y prueba, que podría abarcar los primeros cinco años a que se refiere el artículo 148.2. Y a nadie se escapa que una operación de la envergadura histórica que tiene la transformación conducente a la nueva planta de nuestros poderes públicos, no puede ser ajena a tanteos y rectificaciones progresivas.

Por lo demás, es laudable objetivo intentar construir un modelo de reparto de poder entre Estado y Comunidades Autónomas que resulte sustancialmente homogéneo - aunque nada obstaría al reconocimiento de algunas singularidades en la extensión o intensidad competencial de algunas Comunidades-, no debe considerarse

(6) Vid. el sentido de esta importante diferenciacion en GARCIA DE ENTERRIA. E.. y Fernandez Rodriguez. T. R.: Curso de Derecho administratio, I. 4. a ed.. Civitas. Madrid. 1983. p. 368 y ss.. y en especial pp. 373 y 374. 
contrario a una eventual mayor diversidad institucional interna de las distintas Comunidades Autónomas, que permitiera plasmar más adecuadamente las reales diferencias existentes entre unas y otras Regiones.

La presente comunicación trata de ofrecer una reflexión sobre lo que pudiera haber sido una de las causas de la actual innecesaria uniformidad institucional de las Comunidades Autónomas todas. Al revisarse su entidad, se pone en cuestión su papel de elemento justificador de un sistema y se abre la puerta a un replanteamiento de la estructura institucional y del modelo funcional de aquellas Comunidades Autónomas que puedan considerarlo oportuno.

\section{DETERMINACION ESTATUTARIA DE LA FUNCION DE LOS PARLAMENTOS AUTONOMICOS}

Como es bien sabido, la Constitución no incluyó pronunciamientos inconclusos, ni sobre el alcance y naturaleza de las potestades y funciones. de las Comunidades Autónomas, ni acerca de su estructura organizativa.

Tan sólo fue más explícita en relación con las Comunidades Autónomas que se constituyeran por el procedimiento del artículo 151, al determinar para ellas, en el artículo 152.1, un modelo de organización institucional autonómica básica, de inspiración inequívocamente parlamentaria, que permitía, con todo, diversas modalidades en su aplicación efectiva. En este modelo se dispone la existencia de una denominada Asamblea Legislativa -aludida también, por cierto, en el art. 69.5 de la Constitución, pero con la alternativa de otro tipo de órganos colegiados superiores-, elegida por sufragio universal, con arreglo a un sistema de representación proporcional que asegure, además, la representación de las diversas zonas del territorio. No se exige expresamente que el sufragio sea directo, a diferencia, por ejemplo, de lo que acontece en la misma Constitución en relación con los Ayuntamientos (art. 140) o el Congreso de los Diputados (art. 68.1). Junto a dicha Asamblea se debía establecer un Consejo de Gobierno con funciones ejecutivas y administrativas - aunque no se precisa si con todas las de esta naturaleza-, y un Presidente, elegido por la Asamblea de entre sus miembros, y nombrado por el Rey, al que corresponde la dirección del Consejo de Gobierno -aunque no necesariamente su designación-, la suprema representación de la respectiva 
Comunidad y la ordinaria del Estado en aquélla, siendo el Presidente y los miembros del Consejo de Gobierno políticamente responsables ante la Asamblea.

Tal estructura orgánica que, como ha quedado insinuado, admitía ya de por sí diversas formalizaciones institucionales, no necesariamente coincidentes con el modelo de relaciones Cortes Generales - Presidente del Gobierno - Gobierno (Legislativo/Ejecutivo) establecido en la Constitución para el Estado, ni con la composición y régimen electoral del Congreso de los Diputados, no resulta constitucionalmente exigible a las Comunidades Autónomas no erigidas por el procedimiento del artículo 151, que son las más. Tal es el sentir más generalizado en la doctrina, aunque haya quien sostenga que el modelo institucional del artículo 152.1 debería aplicarse a todas las Comunidades Autónomas con potestad legislativa propia o estatutaria (7). Cabria, incluso, afirmar que las Comunidades erigidas por el artículo 151 inicialmente, podrían ulteriormente, por la vía de la reforma estatutaria, adoptar una organización distinta de la prevista en el artículo 152, si se interpreta literalmente la dicción del artículo 152.1, que puede entenderse referida precisamente y con exclusividad a los Estatutos aprobados por el procedimiento del artículo 151, no necesariamente coincidente con el que se prevea en dichos Estatutos para su revisión o modificación, dentro de lo previsto en el artículo 152.2 (8).

Lo cierto es, sin embargo, que hoy por hoy el modelo institucional básico delineado en el artículo 152.1 es el que se ha aplicado a todas las Comunidades Autónomas. Por añadidura, en todas ellas el sistema electoral para la Asamblea se ha uniformado en términos de sufragio directo, y la designación del Consejo de Gobierno se ha puesto en manos del Presidente. En la Asamblea se ha residenciado, al modo de los Parlamentos estatales, la potestad legislativa, y en el Consejo de Gobierno la potestad ejecutiva, con inclusión de la reglamentaria. A esta generalizada uniformidad orgánica de las Comunidades Autónomas no son ajenos los Pactos Autonómicos entre el Gobierno de UCD y la oposición del PSOE,

(7) Vid. en la linea de la interpretación más difundida, VANDELLI, L.: El ordenamiento español de las Comunidades Autónomas, IEAL. Madrid, 1982, p. 236 y ss.

(8) MUÑZ MACHADO, S. ha destacado la "curiosa paradoja» que resultaria de entender que los poderes de autoorganizacion de las Comunidades de autonomia maxima estan más limitados o condicionados que los de las Comunidades de segundo grado, si bien no formula una interpretación alternativa (cfr. su Derecho público de las Comunidades Autónomas, II. Civitas, Madrid. 1984. p. 25). 
en la primavera de 1981, que siguieron las pautas sentadas por el Informe de la Comisión de Expertos sobre Autonomías, más conocida como Comisión «Enterria» (9).

Los diversos Estatutos configuraron así un esquema de gobierno basado en la división de Poderes y el régimen parlamentario tradicional, similar al estatal, si se exceptúa la previsión de una sola Cámara Legislativa, constituida al modo del Congrezo de los Diputados, sin ninguna representación territorial del tipo de la que se hace parcialmente presente en el Senado (10).

El Parlamento Vasco (EV, art. 25 y ss.), el Parlamento de la Generalidad de Cataluña (EC, art. 30 y ss.), el Parlamento Gallego (EG, art. 10 y ss.), el Parlamento de Andalucía (EA, art. 25 y ss.), la Junta General del Principado de Asturias (EAs, art. 23 y ss.), la Asamblea Regional de Cantabria (ECan, art. 9 y ss.), la Diputación Regional de La Rioja (ER, art. 17 y ss.), la Asamblea Regional de Murcia (EMu, art. 21 y ss.), las Cortes Valencianas (EVal, art. 10 y ss.), las Cortes de Aragón (EAr; art. 12 y ss.), las Cortes de Castilla-La Mancha (ECM, art. 9 y ss.), el Parlamento Canario (ECr, art. 8 y ss.), la Asamblea de Extremadura (EE, art. 20 y ss.), el Parlamento de Baleares (EB, art. 19 y ss.), la Asamblea de Madrid (EM, art. 9 y ss.), las Cortes de Castilla y León (ECL, art. 9 y ss.), e incluso el Parlamento o Cortes de Navarra (LORARFN, art. 11 y ss.), a pesar de las diferencias de denominación y de algunas otras que no es éste el momento de comentar, se han configurado a la manera de los Parlamentos tradicionales en los Estados con régimen parlamentario. El hecho de que en varias Comunidades no se haya utilizado la denominación de Parlamento o la equivalente entre nosotros de Cortes, y se haya optado por nombres históricos como el de la Junta General del Principado de Asturias, o el más común de Asamblea, no tiene mayor trascendencia práctica.

Todos estos Parlamentos o Asambleas Legislativas tienen esta-

(9) Cfr. Informe cit.. editado por CEC, Madrid, mayo 1981, pp. 24 y ss., y 101 y ss. Se ha analizado poco aun la repercusion práctica de las medidas de limitacion del funcionamiento de las Asambleas recomendadas por la Comision de Expertos y efectivamente aplicadas en los Estatutos de las Comunidades de autonomia lenta. Se recordara que la Comisión que presidio Garcia de Enterria tenia como Secretario a Muñoz Machado: Vicesecretario. a Sanchez Moron, y Vocales: Cosculluela Montaner. Tomás Ramón Fernández. QuadraSalcedo y Sosa Wagner.

(10) Vid. sobre esta cuestion. VANDELLI, L.: El ordenamiento español..., cit. p. 243 y ss.. donde incluye breves referencias interesantes al Derecho italiano como elemento comparativo. 
tutariamente reconocido el ejercicio de la potestad legislativa, la aprobación de los presupuestos y el impulso, orientación y control de la acción del Gobierno regional respectivo, así como la elección del Presidente de la Comunidad Autónoma, el cual nombra y separa libremente a los miembros del Gobierno por él presidido.

$\mathrm{Su}$ configuración responde, pues, aparentemente, desde un punto de vista formal, a la de auténticos Poderes legislativos, con cuantas consecuencias ello implica en este orden.

Sólo en algunos - muy pocos- Estatutos, con alguna semejanza a lo que de modo general ocurre en Italia, se ha establecido que los Parlamentos autonómicos, además de dictar leyes o adoptar acuerdos con rango de Ley, puedan aprobar reglamentos propiamente dichos, esto es, disposiciones de carácter administrativo. Es el caso del Estatuto de Asturias, cuyo artículo 23.2 dispone que «en las materias en que sólo corresponde al Principado de Asturias la ejecución de la legislación del Estado, la Junta General podrá ejercer, en todo caso, la potestad reglamentaria para la organización de los servicios, en los términos previstos en el artículo 12 del presente Estatuto" (esto es, "en los términos que establezcan las leyes y normas reglamentarias que en desarrollo de su legislación dicte el Estado»), añadiendo el artículo 33.1 que al Consejo de Gobierno le corresponde «la potestad reglamentaria no reservada en este Estatuto a la Junta General» (11).

Es el caso también del Estatuto de La Rioja, cuyo artículo 17b) asigna a la Diputación General «el desarrollo de la legislación del Estado en aquellas materias que así le corresponda», precisando el artículo 23 que al Consejo de Gobierno le compete «el ejercicio de la potestad reglamentaria no reservada por este Estatuto a la Diputación General».

En líneas generales, por tanto, el órgano que representa al pueblo de cada Comunidad Autónoma ha quedado acantonado en los cometidos característicos de las Asambleas legislativas o parlamentarias, reproduciéndose el modelo que ofrece en nuestro propio Derecho positivo el Congreso de los Diputados, en sí mismo

(11) El Proyecto del Estatuto asturiano conferia aun con alguna mayor amplitud una parte de la potestad reglamentaria a la Junta General. sin limitarla a los aspectos "domesticos". como finalmente se impuso. un poco bajo "el espiritu de la LOAPA".

En relacion en general con este tema. vid. B. SSOLS COMA. M.: "Las diversas manifestaciones de la potestad reglamentaria en la Constitucion". en La Constitucion Española y las Fuentes del Derocho, vol. I. IEF. Madrid. 1979. p. 355 y ss. 
y en su relación con el Gobierno y la Administración de éste dependiente. Ello se ha hecho así, sin duda, porque se ha creído que era la mejor manera de potenciar y dignificar políticamente a Regiones y Nacionalidades, pero es cuestionable que tal sea, efectivamente, el resultado alcanzado y alcanzable si se analizan las cosas detenidamente y no nos damos por satisfechos simplemente con la grandilocuencia de las expresiones verbales y lo aparatoso de los montajes institucionales.

\section{UNA POTESTAD LEGISLATIVA FORMAL, PERO SUBORDINADA}

Como hemos dicho, todos los Estatutos -y la Reintegración y Amejoramiento del Régimen Foral de Navarra- han otorgado a las Asambleas o Parlamentos de las respectivas Comunidades Autónomas, potestad legislativa.

Esa potestad legislativa reúne, desde un punto de vista formal, unas características similares a las que, desde la implantación del Estado constitucional en España, y salvo el breve paréntesis de la II República - y el aún más corto de la primera - se venía considerando como potestad exclusiva del órgano legislativo del Estado.

Bajo nuestro actual ordenamiento, en efecto, las leyes autonómicas poseen una eficacia jurídica que responde a los caracteres de la fuerza de Ley.

Sin embargo, sus efectos jurídicos quedan sujetos, no sólo a ciertas limitaciones derivadas del principio de competencia, ya de por sí muy importantes, sino, sobre todo, a la necesaria subordinación que deriva del principio de primacía relativa de la legislación estatal.

Las leyes autonómicas, ciertamente, se imponen a los Tribunales de Justicia con la misma irresistibilidad y obligatoriedad que las leyes estatales, de modo que se les aplica de lleno lo previsto en el artículo 163 de la Constitución y preceptos concordantes de la Ley Orgánica del Tribunal Constitucional, debiendo los jueces plantear ante éste la correspondiente cuestión de inconstitucionalidad, cuando consideren que puedan ser contrarias a la Constitución y de su validez dependa el sentido que deba darse al fallo en un proceso determinado. Los jueces no pueden, por sí mismos, ni inaplicar las leyes autonómicas ni, menos aún, pronunciarse sobre su nulidad total o parcial, marcándose con ello una neta diferencia 
respecto a su posición ante los reglamentos o disposiciones normativas de carácter administrativo, sometidos, como bien se sabe, al control de los jueces, en aplicación hasta hace poco del artículo $7 .^{\circ}$ de la vieja Ley, Orgánica Provisional del Poder Judicial, de 1870 y -desde la entrada en vigor de la nueva Ley Orgánica del Poder Judicial, de 1 de julio de 1985 - del artículo $6 .^{\circ}$ de esta nueva Ley, así como del artículo 106 de la Constitución y, muy especialmente, de cuanto al respecto dispone la vigente Ley reguladora de la Jurisdicción contencioso-administrativa de 1956.

Sólo el Tribunal Constitucional puede, en consecuencia, juzgar definitivamente sobre la validez de las leyes autonómicas. El artículo 153 a) del texto constitucional le atribuye, en efecto, expresamente, el control relativo a la constitucionalidad de las disposiciones normativas con fuerza de Ley de los órganos de las Comunidades Autónomas, entre las que incuestionablemente hay que situar las leyes autonómicas. Y la Ley Orgánica del Alto Tribunal confirma en su artículo 27 que son susceptibles de declaración de inconstitucionalidad, por su parte, "las leyes, actos y disposiciones normativas con fuerza de Ley de las Comunidades Autónomas» (letra e) del apartado 2), aclarando el artículo 28 que "para apreciar la conformidad o disconformidad con la Constitución de una Ley, disposición o acto con fuerza de Ley del Estado o de las Comunidades Autónomas, el Tribunal considerará, además de los preceptos constitucionales, las leyes que, dentro del marco constitucional, se hubieran dictado para delimitar las competencias del Estado y las diferentes Comunidades Autónomas o para regular o armonizar el ejercicio de las competencias de éstas".

Esta característica obligatoriedad de las leyes se traduce, asimismo, en primacía sobre cualesquiera reglamentos y normas administrativas, aunque también en este aspecto deban tenerse en cuenta las consecuencias del principio de competencia en cuanto condicionante básico de validez en el ejercicio de cualesquiera potestades normativas, que determina su distribución entre el Estado, eventualmente otras instancias superiores, de tipo supranacional, y las Comunidades Autónomas -e incluso las Administraciones locales-, en razón de distintos ámbitos objetivos predeterminados.

El principio de que la Administración «no podrá dictar disposiciones contrarias a las leyes, ni regular, salvo autorización expresa de una ley, aquellas materias que sean de la exclusiva competencia de las Cortes", proclamada en el artículo 26 de nuestra Ley de 
Régimen Juridico de la Administración del Estado, de 1957, y en otros textos legales, es de plena aplicación a las relaciones entre Administración pública y leyes autonómicas, dejando siempre a salvo -insistimos- los correspondientes círculos competenciales de los diversos Poderes públicos normativos.

De ahí también que la doctrina considere, en línea de principio, que las leyes autonómicas pueden satisfacer las exigencias constitucionales de la reserva de ley ordinaria, aunque igualmente por razones competenciales, este principio tenga asimismo sus límites (12).

$\mathrm{Y}$ si de los efectos de las leyes pasamos al procedimiento con que se procede a su aprobación y promulgación (13), nos encontramos, igualmente, con un tratamiento que reproduce exigencias tradicionales de la actividad legislativa estatal: iniciativa privilegiada del Gobierno en forma de proyectos de ley, admisión de proposiciones de ley de los miembros de las Cámaras y de otras iniciativas legislativas como la popular o, incluso, en algunos casos, la municipal -lo que es original de algunos Estatutos de Autonomía uniprovinciales-, procedimiento de enmiendas, deliberaciones y votaciones sucesivas como el usual en el Parlamento nacional y, en fin, promulgación en nombre del Rey, por el Presidente del Ejecutivo y de la Comunidad Autónoma, seguida de su publicación en los «Boletines Oficiales» de la Comunidad Autónoma y del Estado (14).

(12) Para Angel Garrorena Morales nuestro ordenamiento constitucional no establece en rigor una reserva de ley, sino un más radical principio de previa ley, de carácter general, que viene luego además reforzado en ciertas materias por una "reserva cualificada a desarrollo material por ley" (cfr. su monografia El lugar de la Ley..., cit., supra, passim, y especialmente pp. 101-108). La mayor parte de la doctrina sigue hablando, sin embargo, de reserva de ley. Es discutible la interpretación de GARRORENA sobre la naturaleza de la potestad reglamentaria reconocida al Gobierno en el articulo 97 de la CE (op. cit., p. 100).

Los limites a que nos referimos en el texto derivan también de la distinción constitucional entre reserva de ley orgánica y reserva de ley ordinaria, siendo la primera, en principio, exclusiva del Estado.

(13) La doctrina subraya la importancia del procedimiento en la definición formal de la ley. Asi, Tomás Villarroya, J.: "Las fuentes del Derecho en las Comunidades Autonomas", en La Constitución Española y las Fuentes del Derecho, vol. I, IEF, Madrid, 1979, página 156 , con cita de VEDEL.

(14) Como se sabe, el articulo 62 de la CE atribuye al Rey la sanción y promulgacion de las leyes |letra a)|. Si cuando la Constitución habla genéricamente de las leyes - por ejemplo, a efectos de reservas materiales de ley-, la doctrina viene entendiendo que pueden considerarse aludidas tanto las del Estado como las de las Comunidades Autonomas, habria que concluir que la intervención del Rey sancionando y promulgando es constitucionalmente necesaria para toda ley, sin que pueda considerarse suficiente el mecanismo previsto en los Estatutos de Autonomia para la promulgación en nombre del Rey por los Presidentes autonómicos, habida cuenta de que la competencia es irrenunciable y no puede ser delegada ni transferida, salvo autorización expresa de una norma del mismo o superior rango de la que 
Pero tras cuanto queda dicho, importa ahora destacar que, a pesar de ese tratamiento que se ha hecho de la potestad normativa de las Comunidades Autónomas como formalmente legislativa, ese mismo carácter formal se encuentra sometido a unos límites, a una subordinación a las leyes estatales que no puede pasarse por alto ni minusvalorarse. Ciertamente se trata de una subordinación relativa, limitada, pero no por ello menos real y general.

Es cierto que todas las leyes - también las del Estado- han perdido aquel carácter soberano que en otro tiempo pudo predicarse de ellas, debido a su sometimiento a un orden constitucional material y formal, que limita al Poder Legislativo y convierte su cometido en auténtica función limitada, en una competencia (15).

Además, bajo nuestro actual ordenamiento constitucional, el Poder Legislativo nacional está también limitado por las competencias que, conforme a la Constitución, se han ido atribuyendo a las Comunidades Autónomas en el orden normativo (e incluso por lo que pudiera entenderse como integrante en este mismo orden de la garantía institucional de la autonomía local propia de las Entidades locales). Una limitación que es una manifestación más de las que impone la Constitución y que no supone en modo alguno una subordinación, sin embargo, del poder de las Cortes Generales al de los Parlamentos regionales: se trata de un límite, pero meramente negativo; no hay subordinación por ello del Poder Legislativo estatal sino a la Constitución.

Pero la potestad legislativa de los Parlamentos autonómicos, además de encontrar el límite - negativo- de la potestad legislativa reservada al Estado, sí que está además subordinada positivamente $a$ ésta. Y aquí está el punto importante, lo que marca una sustancial diferencia entre ambas potestades «formalmente» legislativas. Porque resulta que la potestad legislativa autonómica es

\footnotetext{
otorga la competencia misma. Por otra parte. al precisarse en el articulo 91 que "el Rey sancionara. en el plazo de quince dias, las leyes aprobadas por las Cortes Generales, y las promulgara $y$ ordenara su inmediata publicacion". podria entenderse a contrario que, en cuanto a la sancion y promulgación de las leyes autonomicas. no estan constitucionalmente sometidas a la misma regla. pudiendose disponer en los Estatutos autonomicos otras previsiones al respecto. Y dado que. conforme al articulo 64. el refrendo de los actos reales le corresponde siempre al Presidente del Gobierno del Estado o a uno de sus Ministros, salvo el caso especial en que ello es competencia del Presidente del Congreso. parece claro que el Ejecutivo estatal podria ejercer - si asi se estableciera estatutariamente - un control de legalidad de las leyes autonomicas. negando el refrendo en la forma y con los efectos que se regularan.
}

(15) Vid. Carré de Malberg. R: La Loi..., cit. passim. y especialmente p. 219. 
una potestad formalmente subordinada, no sólo a la Constitución sino también a la potestad legislativa de las Cortes Generales. Porque -insistimos - no es únicamente que, en virtud de la distribución competencial entre Estado y Comunidad Autónoma, ésta deba mantenerse, como le ocurre al Estado, dentro de su limitada competencia; es que, en ese reparto competencial, ocurre que el Estado ostenta siempre, por lo menos, potestad normativa para regular los aspectos más básicos, las cuestiones fundamentales, los principios desde los que puede vertebrarse u orientarse el conjunto de la ordenación, y a eso va a quedar subordinada la normativa autonómica. No hay campo de la realidad en el que no incida la competencia estatal de establecer al menos unas normas primarias, sola y directamente vinculadas a la Constitución. $Y$, en último extremo, la técnica de las leyes armonizadoras del artículo 150.3 de la CE sirve como cláusula de cierre del sistema, garantizando la unidad del superior interés general nacional mediante la supremacía del ordenamiento estatal.

Aunque se hable de materias atribuidas a la exclusiva competencia de Comunidades Autónomas, sabido es que tal expresión contiene una fuerte dosis de ambigüedad, como lo tiene declarado el Tribunal Constitucional. E incluso cuando efectivamente, en cuanto tal materia legalmente delimitada, pueda pertenecer en exclusiva a la potestad de una o varias Comunidades Autónomas, resultará que la realidad acotada por ella desde una cierta perspectiva conceptualizadora cae también bajo el alcance de otra u otras materias, conceptualizadas desde perspectivas diferentes, que ya no son de la exclusiva competencia de esas Comunidades Autónomas, cayendo bajo la superior ordenación, al menos básica, del Estado. En este sentido, la reserva competencial al Estado del artículo 149.1.1. ${ }^{\mathrm{a}}$, al referirse a las condiciones básicas que garanticen la igualdad de todos los españoles en el ejercicio de los derechos $y$ en el cumplimiento de los deberes constitucionales, está marcando un ámbito material tan general que, salvo quizá ciertas cuestiones puramente organizativas, ningún campo de la realidad social y económica - jurídica - se escapará a su alcance, posibilitando así la universal y superior presencia ordenadora del Estado. La agricultura o el urbanismo caen así, por ejemplo, bajo la superior e indeclinable supremacía del Estado para regir las condiciones básicas que permitan y garanticen una igualdad en el ejercicio del derecho de propiedad (art. $33 \mathrm{CE}$ ) o en el cumplimiento del deber 
de sostener los gastos y cargas públicas (art. $31 \mathrm{CE}$ ), por no referirnos sino a alguno de los derechos y deberes constitucionales más destacables, afectados por las materias agrícola y urbanística (16).

En conclusión: la potestad legislativa autonómica está dotada del efecto jurídico de la fuerza de ley, en su dimensión activa y en la posición que se reconoce a sus normas ante el Poder Judicial, e incluso en sus consecuencias procedimentales; pero el valor de sus leyes se encuentra netamente afectado por la debilidad pasiva que ostentan frente a las normas primarias de la potestad legislativa superior del Estado, aun contando con los límites competenciales que pueden obligar a ésta a mantenerse en el terreno de los principios o de las bases (17). Quien dispone de los principios básicos tiene la llave de la ordenación entera, aunque no pueda entrar en concreciones particularizadas.

De ahí, en fin, que se trate, sí, de una potestad legislativa formal, pero que incluso en cuanto tal aparezca con la importante singularidad de aparecérsenos en su mismo carácter formal como subordinada y no meramente limitada.

Esa subordinación contradice la propia significación formal tradicional o clásica de la potestad legislativa y traduce una realidad política trascendental: el hecho de la subordinación de las colectividades regionales - y nacionalitarias - a la superior comunidad nacional, única depositaria de la soberanía (art. 1.2 CE), cuya unidad garantiza el ordenamiento constitucional en un sistema político de Estado unitario, aunque limitado y respetuoso con ámbitos competenciales propios reconocidos a las autonomías regionales y -en menor grado- a las locales. La unidad nacional se manifiesta asi en nuestro caso en unidad de ordenamiento juridico, plasmada cuando menos en unos mismos principios juridicos ordenadores, que se imponen a todos y que se establecen por el legislador estatal $-\mathrm{y}$ no sólo a nivel constitucional-, aunque admitan un desarrollo, una pormenorización multiforme en diver-

(16) Sobre el 149.1.1 a CE, vid. Carro Fernandez-Valmayor, J. L.: "Contenido y alcance de la competencia del Estado definida en el articulo 149.1.1. a de la Constitución", en $R E D C$, num. 1, enero-abril 1981. Nosotros nos ocupamos tambièn ya del papel de este precepto en "Poderes de ordenación economica del Principado de Asturias", en Estudios sobre el Provecto de Estatuto de Autonomia para Asturias, Caja de Ahorros de Asturias, Oviedo, 1982, p. 100.

(17) Vid. RUBio Llorente, F.: "Rango de Ley, Fuerza de Ley, Valor de Ley», RAP, numeros 100-103, I, p. 417 y ss., que representa una reflexión breve y reciente sobre estos conceptos en su utilización por la Constitución de 1978. 
sos campos, por obra de los Poderes públicos regionales o -en menor medida- locales (18).

Esta subordinación formal de las leyes autonómicas a las estatales - aún relativa - $\mathrm{y}$, por lo mismo, la de la potestad legislativa autonómica a la estatal, puede aún confirmarse examinando con algún mayor detalle el ámbito objetivo del poder legislativo autonómico, cuyá consideración pone, además, de relieve la trascendental calidad de los límites competenciales dentro de los cuales ha de desenvolverse.

\section{AMBITO OBJETIVO DE LAS LEYES AUTONOMICAS (MATERIAS Y NIVELES DE REGULACION)}

Es normal que, incluso en las materias en que los Estatutos dicen atribuir a las correspondientes Comunidades Autónomas competencia exclusiva $-\mathrm{y}$ por tanto potestad normativa para una presunta regulación integral de aquéllas-, se añada como límite expreso una referencia al marco de las competencias reservadas constitucionalmente al Estado, especialmente en el artículo 149.

Por ello, toda comprensión realista del ámbito objetivo de la potestad legislativa autonómica debe arrancar del examen de esas reservas competenciales del Estado.

Hay que recordar que la competencia normativa reservada al Estado en todo caso alcanza de distinta manera o con diversa intensidad a muy variadas materias. Hay, en primer término, materias reservadas a la integra regulación normativa del Estado (a); hay, después, importantes materias en las que se ha reservado al Estado la legislación a secas (b); y hay, en tercer lugar, materias respecto de las cuales la Constitución ha retenido en el Estado únicamente las bases de su regulación (c). Veámoslo sucintamente.

a) La competencia estatal para la íntegra regulación normativa - y además para la ejecución o/y administración en exclusivase extiende, ni más ni menos, a las siguientes materias: nacionalidad, inmigración, emigración, extranjería y derecho de asilo $\left(149.1 .2 .^{a}\right)$, relaciones internacionales (art. 149.1.3. ${ }^{\mathrm{a}}$ ), Defensa y Fuerzas Armadas $\left(149.1 .4 .^{\mathrm{a}}\right)$, Administración de Justicia

(18) La naturaleza de la potestad legislativa autonómica viene a ser una manifestación más de la realidad constitucional de que el español es un Estado unitario. Vid. al respecto, López Rodo, L.: Estado y Comunidades Autónomas, Abella, Madrid, 1984, p. 19 y ss. 
$\left(149.1 .5 .^{\mathrm{a}}\right)$, comercio exterior $\left(149.1 .10{ }^{\mathrm{a}}\right)$, sistema monetario, con divisas, cambio'y convertibilidad $\left(149.1 .11 .^{a}\right)$, determinación de la hora oficial $\left(149.1 .12 .^{a}\right)$, Hacienda general y Deuda del Estado $\left(149.1 .14 .^{a}\right)$, fomento y coordinación general de la investigación científica y técnica $\left(149.1 .15 .^{a}\right)$, sanidad exterior $\left(149.1 .16 .^{a}\right)$, marina mercante y abanderamiento de buques, iluminación de costas y señales marítimas, puertos de interés general, aeropuertos de interés general, control del espacio aéreo, tránsito y transporte aéreo, servicio metereológico y matriculación de aeronaves $\left(149.1 .20 .^{a}\right)$, ferrocarriles $y$ transportes terrestres inter o suprarregionales $\left(149.1 .21 .^{\mathrm{a}}\right)$, tráfico y circulación de vehículos a motor, correos y telecomunicaciones, cables aéreos, submarinos y radiocomunicación $\left(149.1 .21 .^{a}\right)$, obras públicas de interés general o suprarregional (149.1.24. ${ }^{\mathrm{a}}$ ), defensa del patrimonio cultural, artístico y monumental español contra la exportación y expoliación $\left(149.1 .28 .^{a}\right)$, estadística para fines estatales $\left(149.1 .31 .^{a}\right)$ y autorización para convocatorias de consultas populares por vía de referéndum (149.1.32. ${ }^{\mathrm{a}}$ ), aparte, naturalmente, aunque no lo diga el artículo 149, cuanto se refiera a la organización institucional del propio Estado.

Si se repara un poco en todas esas materias íntegramente reservadas al Estado, se reconocerá que a la postre se trata de cuanto se refiere a Relaciones internacionales y Defensa de la Nación, Justicia, Moneda y Hacienda nacionales, Comunicación interna nacional y salvaguarda de la Cultura, asimismo, nacional. Son los grandes cometidos del Estado, la expresión actual de aquellos derechos privativos del Rey que «le pertescen por señorío natural: Justicia, Moneda, Fonsadera y suos Yantares», según la antigua y conocida fórmula del Fuero Viejo, a los que se han añadido los temas, tan importantes hoy, de la Comunicación y la Cultura, fundamentalmente.

Pero, además de las materias expresadas, se ha reservado, asimismo, integramente al Estado el régimen jurídico de otra serie de materias, sin perjuicio de que a las Comunidades Autónomas se les pueda atribuir competencia ejecutiva en ellas. Se trata, pues, también de reserva al Estado de toda potestad normativa -legislativa y reglamentaria - en esos campos: aduanas $\mathrm{y}$-aranceles (149.1.10. $\left.{ }^{\mathrm{a}}\right)$, sistema económico de la Seguridad Social $\left(149.1 .17 .^{\mathrm{a}}\right)$, régimen general de comunicaciones $\left(149.1 .21 .^{\mathrm{a}}\right)$, producción, comercio, tenencia y uso de armas y explosivos, y seguridad pú- 
blica $\left(149.1 .26 .^{\mathrm{a}}\right.$ y $\left.29 .^{\mathrm{a}}\right)$, museos, archivos y bibliotecas de titularidad estatal $\left(149.1 .28 .^{a}\right)$ y condiciones de obtención, expedición y homologación de títulos académicos y profesionales $\left(149.1 .30 .^{a}\right)$. Un listado heterogéneo, que viene a complementar el que anteriormente hemos relacionado y en el que, junto a los aspectos relacionados con el Comercio exterior y la Cultura o la Comunicación, son de destacar la importancia de la Seguridad interior y la atención a la Seguridad Social, tan característica del Estado social.

b) Decíamos que hay, en segundo término, una reserva constitucional al Estado no. ya, en principio, de la entera normativa sobre unas materias, sino tan sólo sobre la legislación relativa a ellas. Es lo que acontece con tan amplios e importantes sectores del ordenamiento, como el mercantil, el penal y penitenciario, el procesal y el laboral, y la mayor parte del civil (art. 149.1.6. ${ }^{\mathrm{a}}, 7 .^{\mathrm{a}}$ y $8 .^{\mathrm{a}}$ ), así como en cuanto se refiere a la propiedad intelectual e industrial, pesas y medidas $\left(149.1 .9 .^{\mathrm{a}}\right.$ y $\left.12 .^{\mathrm{a}}\right)$, productos farmacéuticos $\left(149.1 .16 .^{a}\right)$, expropiación forzosa $\left(149.1 .18 .^{a}\right)$, recursos y aprovechamientos hidráulicos de aguas interregionales $\left(149.1 .22 .^{\mathrm{a}}\right) \mathrm{y}$, en fin, el dominio público estatal que, al menos según el artículo 132.2 de la Constitución, ha de incluir la zona marítimo-terrestre, playas, mar territorial y los recursos naturales de la zona económica y la plataforma continental, así como cuanto se refiere, lógicamente, al Patrimonio del Estado y al Patrimonio Nacional, en virtud de lo dispuestos en ese mismo artículo 132, en su ap. $3 .^{\circ}$.

El alcance de esta reserva al Estado de la legislación en todo cuanto queda dicho, podía y aun debía, a nuestro juicio, haberse interpretado rigurosamente en un sentido juridico-formal, de modo que todo cuanto en las materias correspondientes formase parte de la reserva de ley o bien hubiera sido ya asumido en el ámbito de la autorreserva legal por las Cortes Generales, o lo fuese en el futuro, sería justamente lo que debería entenderse como reservado a la competencia normativa del Estado y de su Poder Legislativo, pudiendo atribuirse a las Comunidades Autónomas, incluso por vía estatutaria, el ejercicio de la potestad reglamentaria para la aplicación, desarrollo o ejecución de dicha legislación, en la medida en que la correspondiente intensidad de la reserva legal lo permitiera o, en fin, con la amplitud con que, según las materias de posible autorreserva, cupiese una deslegalización.

Sin embargo, el Tribunal Constitucional se ha encaminado por 
una interpretación material y no formal del término legislación, a estos efectos, lo que nos parece criticable. Entre otras cosas, porque ello supone no tomar suficientemente en consideración un obligado criterio sistemático -el contexto de que habla el art. 3.1 del Código Civil- en el que puede percibirse la significación formal que reviste en nuestra Carta Magna cuanto tiene que ver con lo legislativo: las múltiples referencias a las leyes, la potestad legislativa del Estado de que habla el artículo 66.2, la asunción en el artículo 85 del término "legislación delegada» como contenido de los «Decretos legislativos» y la referencia a "disposiciones legislativas provisionales" como contenido de los Decretos-leyes en el 86.1, la expresión "iniciativa legislativa» del artículo 87, o de "medidas legislativas» del artículo 94.1.e), la misma alusión a la «legislación sobre Régimen Local» del artículo 148.1.2. ${ }^{a}$, en contraste con las funciones de la Administración sobre las Corporaciones locales, la intencionalidad generalmente reconocida a la denominación de Asamblea Legislativa para ese órgano de las Comunidades Autónomas constituidas por el artículo 151, que se prevé en el artículo 152.1, el sentido en que suele interpretarse lo dispuesto por el artículo 150.1 sobre la delegación legislativa en favor de las Comunidades Autónomas por la vía extraestatutaria de las leyes-marco, etcétera.

Pensamos que la interpretación del Tribunal Constitucional debería rectificarse para admitir, en el sentido expuesto, que las Comunidades Autónomas pudieran asumir potestad reglamentaria propiamente dicha - «jurídica», en la vieja terminología de la doctrina alemana - en las materias cuya legislación queda constitucionalmente reservada al Estado. Lo que, por otro lado, no obstaría al reconocimiento, en cuanto fuere necesario, de una potestad reglamentaria del Estado en esas materias cuando pueda requerirlo la necesaria protección del interés general nacional encomendado al Estado o las mismas características técnicas del asunto de que se trate. Y ello aun cuando no haya sido así previsto expresamente por la legislación correspondiente.

Aparte de lo dicho, la Constitución reserva, por otra parte, a la exclusiva competencia legislativa del Estado -o refuerza la reserva que acabamos de considerar en algunos casos- cuanto constituye el ámbito propio de las leyes orgánicas configuradas en el artículo 81 de la Constitución. Hay que exceptuar, no obstante, parcialmente de esta reserva, el desarrollo de los derechos 
y libertades públicas en materia de enseñanza, a que se refiere el artículo 27 del texto constitucional, y el régimen de los derechos fundamentales y libertades públicas implicados en los medios de comunicación social, ya que el artículo 149.1, en sus números 30 y 27 , respectivamente, muestra la voluntad constitucional de admitir que el desarrollo normativo de una regulación básica establecida en esos derechos y libertades por el Estado - por las Cortes Generales- sea deferido a las Comunidades Autónomas, lo que, por cierto, ya ha sido expresamente confirmado por el Tribunal Constitucional desde su Sentencia sobre la LOECE, de 13 de febrero de 1981 , en cuanto a la enseñanza.

La reserva de ley orgánica -en cuanto no deba ser modulada por aplicación del artículo 149, o de otros preceptos que obligaran a conclusión similar a la que acabamos de exponer- implica, de suyo, una plena reserva a la potestad legislativa estatal, con la consiguiente competencia exclusiva del Estado sobre la legislación de todos los derechos fundamentales y libertades públicas -arts. 15 a $29 \mathrm{CE}$ - . La reserva del artículo 149.1.6. ${ }^{a}$ sobre la legislación penal queda así, por cierto, reforzada en favor del Estado. Y cabe, además, destacar que, en virtud de lo dispuesto en el art. 157.3, en coherencia con lo determinado por el artículo 133, la regulación de las competencias financieras de las Comunidades Autónomas es competencia asimismo del Estado, por serlo de la ley orgánica.

En todas las materias en que el Estado se ha reservado la legislación es claro que no puede entrar el poder legislativo autonómico, aunque -como hemos dicho- sí que debería poder hacerlo el reglamentario. Pero esta potestad reglamentaria debería haberse reconocido a las Asambleas, para que no se produzca el curioso resultado de una reserva normativa a favor de los Ejecutivos autonómicos, contraria al reparto de funciones entre Asamblea y Gobierno, que debería extraerse del principio de participación. La dominante preocupación por hacer a las Asambleas órganos formalmente legislativos ha "impedido» reconocer a éstas competencia para intervenir normativamente en esas materias sobre las cuales las Comunidades Autónomas no podrían tener potestad legislativa, pero sí reglamentaria.

Por lo demás, cabe destacar la estrecha vinculación de las competencias legislativas reservadas en las materias reseñadas al Estado, con los núcleos de potestad pública más tradicionalmente 
asignados al Poder público estatal, como expresión e instrumento de una colectividad soberana.

c) Hay, finalmente, otras materias sobre las cuales la Constitución solamente ha reservado al Estado la legislación básica. Esta es, en concreto, la expresión que utiliza textualmente, en algunos casos, el artículo 149.1. Así cuando atribuye al Estado competencia exclusiva sobre la legislación básica de la Seguridad Social (materia $17 . .^{\mathrm{a}}$ ), o sobre contratos y concesiones administrativas y el sistema de responsabilidad de todas las Administraciones públicas (materia $18 .^{\mathrm{a}}$ ), y protección del medio ambiente o montes, aprovechamientos forestales y vías pecuarias (materia $23 .^{a}$ ).

El mismo artículo 149.1 reserva otras veces al Estado la competencia exclusiva sobre «la regulación de las condiciones básicas que garanticen la igualdad de todos los españoles". en cierta materia, o bien sobre «las normas básicas» de otras. El primer caso se refiere al ejercicio de los derechos y al cumplimiento de los deberes constitucionales (materia $1 .^{a}$ ); y debe destacarse lo omnicomprensivo de la referencia (que incluirá, por tanto, cualesquiera derechos y deberes constitucionales de los españoles, incluidos, por ejemplo, los que se aluden en el artículo $3 .^{\circ}$ de la Constitución); la segunda expresión se utiliza ën relación con el régimen de prensa, radio y televisión $\mathrm{y}$, en general, de todos los medios de comunicación social (materia $27 .^{\mathrm{a}}$ ) y con el desarrollo del artículo 27 de la Constitución, cuyo objeto es la educación y la enseñanza (materia $30 .^{a}$ ), es decir, por tanto, en relación con el ejercicio de algunos derechos y libertades fundamentales de los garantizados constitucionalmente al máximo nivel, lo que supone una cierta reduplicación de la genérica reserva proclamada en la materia $1 .^{\mathrm{a}}$.

Aún se emplean otras fórmulas en el artículo 149.1, de indudable proximidad significativa respecto de las anteriores, como cuando en la materia $11 .^{\text {a }}$ se reservan al Estado "las bases de la ordenación del crédito, banca y seguros», o en la $13 .^{\text {a }}$ «las bases (...) de la planificación general de la actividad económica», en la $16 .^{\text {a }}$ "las bases (...) de la sanidad», en la $18 .^{\text {a }}$ "las bases del régimen jurídico de las Administraciones públicas y del régimen estatutario de sus funcionarios», o, en fin, las «bases del régimen minero y energético" de la materia 25 . $^{\mathrm{a}}$.

Obsérvese bien que en la mayor parte de estos casos la locución empleada une el término bases al concepto de ordenación o al equi- 
valente de régimen jurídico o de régimen estatutario (para el caso específico del de los funcionarios). A lo que puede añadirse que la expresión "bases de la sanidad» goza entre nosotros de una tradición que la vincula a un texto legislativo realmente básico en la materia, la Ley de Bases de Sanidad Nacional, de 25 de noviembre de 1944, que no fue en modo alguno una ley de bases en sentido técnico - una ley de delegación legislativa-, sino una ley ordinaria directamente aplicable; $o$, en fin, que la noción de bases de la planificación económica general difícilmente podrá desligarse de la exigencia de un nivel legislativo formal, máxime cuando hoy el artículo 131 de la Constitución reserva expresamente a la ley tal planificación.

Está, por ello, plenamente justificado entender que en todos los casos relacionados lo que se reserva al Estado es una ordenación jurídica básica, una normativa básica. En estas materias, las Comunidades Autónomas no pueden asumir estatutariamente sino competencias normativas de desarrollo o pormenorización, subordinadas a los principios y criterios básicos que fije el Estado, aparte las competencias propiamente de ejecución administrativa por vías no normativas que puedan, asimismo, recibir.

Frente a lo que se ha indicado en algunas sentencias del Tribunal Constitucional y ha admitido alguna doctrina, no creo que en el concepto de bases empleado en el artículo 149.1 para reservar ciertas competencias al Estado, puedan con rigor incluirse decisiones o resoluciones no normativas. Tampoco creo que entren en dicha noción aspectos normativos que no tengan carácter básico del ordenamiento pero que puedan venir requeridos para el ejercicio por el Estado de alguna función administrativa exigida en la materia por el interés general nacional, cuya reserva al Estado sí que, en cambio, puede eventualmente considerarse algo básico del ordenamiento correspondiente $\mathrm{y}$, por tanto, de necesaria inclusión en la normativa básica de exclusiva competencia estatal.

A la normativa básica a que nos venimos refiriendo debe reconocérsele rango formal legislativo, por lo que la correspondiente reserva competencial en favor del Estado puede, efectivamente, ser considerada como relativa a la legislación básica, entendidos estos términos en sentido formal y material al mismo tiempo. Correctamente, el Tribunal Constitucional exige que sean las Cortes Generales quienes establezcan lo que haya de entenderse por básico. El examen de las materias alcanzadas por esta reserva competen- 
cial descubre enseguida que se trata de materias reservadas a la ley por otros preceptos constitucionales, cuando no es el mismo artículo 149.1, el que, al hablar expresamente de legislación básica, está queriendo exigir ese nivel formal.

No obsta a esta conclusión el que, como viene haciendo el Tribunal Constitucional, en tanto las Cortes Generales no dicten la legislación básica, pueda y deba deducirse esa normativa básica del conjunto del ordenamiento jurídico vigente, independientemente de que las normas concretas de que se trate hayan sido establecidas en su día, no por el Poder Legislativo, sino por la Administración. Es sabido que la Constitución, al reservar materias a la ley, congela a ese nivel formal la normativa correspondiente, de modo que en adelante no podrá ya ser modificada, derogada o alterada sino mediante ley formal.

Pero por encima de todas estas rápidas consideraciones (19), lo que en este momento interesa sobre todo es destacar esta doble observación: que en las materias en que se reserva constitucionalmente al Estado solamente la legislación básica - sólo y nada menos-, es claro que las Comunidades Autónomas podrán asumir en sus Estatutos una competencia normativa considerablemente más amplia que la que puede atribuírseles en las materias en que toda la legislación corresponde al Estado; y, en segundo término, que la retención de esa potestad legislativa básica otorga al Estado un poder político trascendental de ordenación primaria, tanto más relevante cuanto realmente las materias a las que se aplica -especialmente la relativa a los derechos y deberes constitucionales- contienen una significación y alcance más generales, abranzando prácticamente toda la realidad social.

Las Comunidades Autónomas podrán, ciertamente, beneficiarse de una reserva de potestad para el desarrollo normativo de la legislación básica estatal, en todo cuanto entre dentro de su respectivo interés, de acuerdo con la fórmula general del artículo 137 del texto constitucional, limitando asi en medida no despreciable

(19) Para un análisis más amplio de la posición del Tribunal Supremo y de la doctrina en la cuestión, vid. SALAS, J.: "Estatutos de Autonomia, Leyes Básicas y Leyes de armonizacion", RAP, nums. 100-103, I, p. 433 y ss.; GARRIDO FALLA, F.: "El desarrollo legislativo de las normas básicas y leyes marco estatales por las Comunidades Autónomas", RAP, núm. 94, enero-abril 1981; GaRCia DE ENTERRIA, E., y FERnÁNDEZ, T. R.: Curso..., I, cit, p. 293 y ss.; MUÑOZ MACHADO, S.: Derecho público..., cit, I, Civitas, Madrid, 1982, p. 417 y ss., y AJA, E., et alii: El sistema juridico de las Comunidades Autónomas, Tecnos, Madrid, 1985, p. 142 y ss. 
el poder regulador del Estado y, en concreto, de las Cortes Generales, pero, al mismo tiempo, al ejercer esa potestad normativa que pueden reservarle los Estatutos, debe subordinarse a la primacía y prevalencia de la legislación básica estatal en la materia. Por eso, la correspondiente potestad normativa autonómica podía muy bien haberse institucionalizado como potestad reglamentaria con reserva reglamentaria, como propuso en su día GoNZÁleZ NAVARRO (20). El haberse formalizado como potestad legislativa no cambia, en rigor, demasiado la naturaleza de las cosas, aunque ello tenga algunos importantes efectos, no necesariamente valorables positivamente.

Tras el examen que acaba de exponerse acerca del marco en que necesariamente habrá de mantenerse la potestad normativa estatutaria de las Comunidades Autónomas - a lo que habría que añadir finalmente la posibilidad de dictar leyes armonizadoras estatales conforme al artículo 150.3 de la Constitución-, no nos parece necesario detenernos ahora en un análisis pormenorizado que viniera a demostrar, punto por punto, el hecho de que no existe parte de la realidad social y económica que pueda corresponder a una exclusiva potestad normativa autonómica. Y ello aun cuando los Estatutos de Autonomía puedan, en ocasiones, otorgar competencia "exclusiva» (siempre "sin perjuicio» de lo establecido en el artículo 149.1 de la $\mathrm{CE}$ ) en relación con algunas materias sobre las que expresamente no hay en la Constitución ninguna reserva a potestad normativa alguna del Estado. La realidad acotada por esas materias coincide siempre con la encajable en otras materias sí explicitadas en el citado artículo 149.1, sobre las cuales el Estado retiene, cuando menos, una potestad de legislación básica.

En una visión de conjunto se destaca, además, que a la potestad normativa estatutaria de las Comunidades Autónomas le queda vedado todo el Derecho penal y todo el Derecho privado - con la excepción relativa a la conservación, modificación y desarrollo de los Derechos forales o especiales en los términos del artículo 149.1.8. ${ }^{\mathrm{a}}$-, el Derecho procesal y parte íntegras importantes del Derecho administrativo, con ser esta rama del Derecho público - junto con lo que pertenece al Derecho "político» en la organización básica de las Comu-

(20) Cfr. González Navarro. F.: "Potestad legislativa del Estado y potestad reglamentaria autonoma de las Nacionalidades y Regiones", en La Constitución Española y las Fuentes del Derecho, II, IEF, Madrid, 1979, p. 1021 y ss., y especialmente p. 1114 y ss. 
nidades Autónomas y en lo relativo al sistema electoral, régimen parlamentario y relaciones entre Parlamentos y Gobierno- donde más amplio juego puede encontrar la autonomía normativa $-\mathrm{y}$ por supuesto administrativa y gestora - de dichas Comunidades. También en materia de Derecho financiero y tributario pueden disponer $\mathrm{y}$, de hecho, disponen de facultades normativas. Pero aun en todos estos campos, nunca puede entrar la potestad normativa autonómica con carácter primario y exclusivo: en cualquier posible regulación jurídica deberá supeditarse a la superior potestad legislativa estatal, al menos en cuanto a los aspectos básicos. Sin olvidar que el origen mismo de esa potestad autonómica se encuentra directamente en un Estatuto de Autonomía, que recibe forma legal mediante su aprobación mediante un acto de la potestad legislativa del Estado, por muy paccionado que sea el procedimiento seguido en tales casos para el ejercicio de dicha potestad y por importantes que sean los condicionamientos para la modificación de los Estatutos que, en efecto ellos mismos - al amparo de la Constitución - hayan establecido.

No olvidamos que, en virtud de lo previsto en el artículo 150.1 de la Constitución, puede delegarse extraestatutariamente competencia legislativa en las Comunidades Autónomas, dentro de los límites y condicionamientos que ese precepto establece. Pero esta posibilidad no altera sustancialmente las cosas. Aunque las Comunidades Autónomas no tuvieran competencia legislativa propia, estatutaria -como tampoco la tiene, en un orden análogo, el Gobierno en el Estado-, podrian igualmente ser beneficiarias de esa posibilidad de recibir potestad legislativa delegada por las correspondientes leyes-marco estatales. Ciertamente podrán dictar entonces eventualmente legislación primaria sobre algún campo de la realidad, pero con sometimiento a los «principios, bases y directrices» de la ley-marco de delegación, y bajo el control de las Cortes Generales, todo ello como expresión, en suma, de la superior responsabilidad que, sobre el uso de la potestad legislativa en tales casos, retiene constitucionalmente el Estado.

Todo lo expuesto muestra el carácter no sólo limitado, sino también relativamente subordinado que tiene en todo caso el objeto material de la potestad legislativa de las Comunidades Autónomas, lo que se traduce, en efecto, en una subordinación relativa a la legislación estatal que penetra la misma naturaleza formal de las leyes autonómicas en los términos ya explicados. 


\section{NATURALEZA DE LA POTESTAD LEGISLATIVA AUTONOMICA}

Ha quedado de manifiesto que la potestad legislativa autonómica configurada en nuestro actual Derecho vigente, reúne una parte importante de las características formales propias tradicionalmente de la potestad legislativa, aunque, a la vez, no deje de presentar muy notables singularidades, incluso desde ese mismo punto de vista jurídico-formal, a consecuencia del juego del principio de competencia $y$, sobre todo, del de primacía relativa de la potestad legislativa estatal, que resulta cabalmente del modo adoptado constitucionalmente para el reparto de competencias entre el Estado y las Comunidades Autónomas. Es su peculiar ámbito objetivo lo que se traduce también en trascendentales peculiaridades formales, que suscitan serios problemas y dudas a la hora de concluir sobre la verdadera naturaleza jurídica de dicha potestad legislativa autonómica.

Como hemos dicho, nunca podrán ser las leyes autonómicas auténticas normas primarias y superiores del ordenamiento, sólo y directamente dependientes de la Constitución (21). Además de que la potestad legislativa autonómica deriva de unas leyes estatales cuales son los Estatutos de Autonomía - por paccionadas que puedan considerarse-, lo que marca ya una no despreciable diferencia con el carácter netamente originario de la potestad legislativa estatal, la potestad autonómica nunca puede ejercerse sobre los principios o criterios más básicos de ordenación de la realidad, que están siempre reservados al Estado, único competente para el desarrollo principal inmediato del orden constitucional. Las leyes autonómicas son, por ello, en cualquier caso, normas secundarias y subordinadas en todo caso y sin excepción.

$\mathrm{Si}$ las leyes se han definido siempre en sentido estricto, sustancial y aun formal, como las normas primarias, directamente conectadas a la Constitución, frente al carácter secundario y esencialmente subordinado de los reglamentos, hay que reconocer que las

(21) Expresamente en contra, sin justificarlo, TOMAS Villaroya, J.: Las fuentes..., citado, p. 157.

Un concepto de ley en sentido técnico como norma primaria, en DE CASTRO y BRAvo, F.: Derecho civil de España, 2. ${ }^{a}$ ed., Parte General, I, IEP, Madrid, 1949. 
leyes autonómicas se asemejan, en este punto fundamental, más a los reglamentos que a las leyes (22).

Tal similitud con los reglamentos administrativos se confirma al observar que, como éstos, las leyes autonómicas «no podrán establecer penas ni imponer exacciones, tasas, cánones, derechos de propaganda y otras cargas similares, salvo aquellos casos en que, expresamente, lo autorice una ley votada en Cortes», dicho sea con los mismos términos empleados por el artículo 27 de la Ley de Régimen Jurídico de la Administración del Estado, de 1957, que obviamente, cuando se refiere a las Cortes está hablando de las Cortes Generales del Estado. Y cabe señalar a este respecto que, en efecto, la potestad fiscal y tributaria derivada de que gozan las Comunidades Autónomas (art. 133.2 de la Constitución), está cuando menos subordinada a la ley orgánica estatal contemplada en el artículo 157.3 del texto constitucional y que la legislación penal, como ya se ha dicho, es materia enteramente reservada al Estado.

Que, en ciertas materias, la competencia normativa estatal quede limitada, en su supremacía, a lo básico, no supone, de suyo, desvirtuar ese carácter sustancialmente reglamentario que venimos atribuyendo a la legislación autonómica, ya que ello, según hemos anteriormente explicado, puede perfectamente comprenderse desde la técnica de la reserva reglamentaria que, en nuestro actual De-

(22) No entendemos por ello como autores como GarRorena, tras definir la ley en nuestro ordenamiento vigente como "expresión de la voluntad soberana del Estado" (lo que puede suponer, por cierto, una exageracion, que es matizada por el mismo autor en otros pasajes), ya que "sólo detrás de ella está el Parlamento como representación de la sociedad, y, en consecuencia, sólo sus mandatos traducen decisiones de soberania" (cfr. GARRORENA MORAles, A.: El lugar de la ley.... cit., p. 97), perteneciendo por lo mismo "al propio imperio de la ley, esto es, a la propia cualidad soberana de las decisiones que comporta, el que éstas no deban conocer más limites que los que a dicha potestad legislativa imponga la Constitucion" (cfr. op. cit., p. 107), "en cuyo lugar es imposible subrogar, por tanto, otro imperio (...) a la hora de la adopcion de las decisiones primeras y soberanas"; afirmen despues que "la Constitucion se ha preocupado de asegurar para ella (para la "ley regional") una misma identidad" (subrayado nuestro), una identidad que es "una misma con la de la ley elaborada por el Parlamento del Estado", por lo que "es posible afirmar que no se trata de dos tipos de leyes distintas, sino de una sola y misma legalidad, diferenciable sólo por su ocasional fuente de produccion, pero nunca por la cualidad de la voluntad que cada una de tales fuentes comporta" (cfr. op. cit., pp. 116 y 118).

Tal planteamiento parece no reparar en la profunda diferencia que hay que establecer, conforme a nuestro ordenamiento constitucional, entre ostentar la representación del pueblo, en quien reside la soberania nacional (arts. 66 y 1.2 de la Constitución), y detentar la representacion del pueblo de una Region o Nacionalidad de las que integran, segun el artuculo $2 .^{\circ}$ del texto constitucional, la Nación española, lo que se traduce en el sistema de reparto competencial adoptado por el ordenamiento constitucional a la hora de distribuir entre Estado y Comunidades Autonomas la potestad normativa. 
recho positivo, se ha formalizado con una reserva para la legislación de desarrollo o incluso como reserva de la íntegra legislación sobre algunas materias, cuyo alcance y contenido queda, a la postre, limitado por su relación subordinada con otras materias sobre las cuales el Estado retiene al menos competencia normativa básica (23). Tales reservas estatutarias no abonan, pues, necesariamente, ni mucho menos, la consideración de la potestad legislativa autonómica como verdadera y propia potestad legislativa, sustantivamente hablando.

En pro de la naturaleza propiamente legislativa de la potestad legislativa de la potestad normativa autonómica, de que venimos tratando, podría argüirse, sin embargo, el hecho de que en algunas materias expresamente reservadas a la ley por nuestra Constitución, la competencia legislativa queda repartida en cuanto a lo básico y en cuanto al desarrollo, respectivamente, entre el Estado y las Comunidades Autonómas. Me refiero a las libertades de enseñanza y de expresión en medios de comunicación social, o al derecho fundamental a la educación, así como a derechos y libertades tan destacados como los de propiedad o libre empresa, o el deber de contribuir al sostenimiento de los gastos públicos, inseparable del correspondiente derecho a hacerlo conforme a los principios del artículo 31. Aquéllos por ser objeto -en cuanto a los aspectos básicos- de ley orgánica, y éstos por ser objeto de la reserva legal del artículo 53.1 de la Constitución y no quedar englobados íntegramente en las reservas al Estado de la totalidad del régimen jurídico, ni de la legislación correspondiente, permiten plantear la cuestión indicada.

Tal cuestión puede, con todo, resolverse sin dificultad especial afirmando que, en una interpretación sistemática de la Constitución, la reserva legal afectaría en tales materias solamente a la regulación básica, pudiendo desarrollarse ulteriormente los correspondientes criterios básicos mediante potestades de naturaleza sustancialmente reglamentaria, secundaria y derivada, o, al menos, por las que en este orden se considerasen constitucionalmente atribuibles a las Asambleas de las Comunidades Autónomas.

(23) Como ejemplo de la matizada posición hermenéutica de nuestro Tribunal Constitucional a la hora de subsumir la realidad en los distintos ámbitos categoriales acotados como materias diversas en la Constitución y en los Estatutos de Autonomia, puede citarse aqui la Sentencia 80/1985, de 4 de julio, del Pleno del TC («BOE» num. 170, Suplemento, 17 julio 1985 , p. 48 ). 
La clave de la cuestión, a nuestro entender, para ser analizada y resuelta fríamente y sin dejarse llevar por preocupaciones excesivamente nominalistas, está en darse cuenta de que el margen real de autonomía política, de autogobierno de una Región o Nacionalidad institucionalizada, no aumenta ni disminuye sólo porque a la potestad normativa se la califique de legislativa o de reglamentaria. Si la actual potestad legislativa autonómica se la hubiese configurado técnicamente como formalmente administrativa, sin que en nada disminuyese su amplitud de objeto, ni su intensidad, ni sus garantías de respetabilidad, cosa perfectamente posible, no habría variado la dimensión real y efectiva de la autonomía regional y nacionalitaria. El rechazo de que ha sido objeto la reserva reglamentaria a nivel del Estado en favor del Gobierno -en parte por defecto de comprensión de la institución, que en ningún caso priva en Francia al Parlamento de su poder de normar los aspectos básicos de cualquier materia-, no encuentra justificación posible en su aplicación a la distribución competencial entre Poder Legislativo estatal y Poder normativo autonómico. Los beneficiarios de dicha reserva no serían unos Ejecutivos distanciados de la representación popular, sino las Asambleas representativas del pueblo de cada comunidad sociopolítica infraestatal a la que constitucionalmente se le reconoce derecho a la autonomía. Dicha reserva no viene a significar otra cosa que la determinación de un reparto en el ejercicio de los poderes normativos entre la representación del pueblo depositario de la soberanía nacional y las representaciones de esos "fragmentos» de ese pueblo que son, a su vez, los pueblos de las unidades territoriales inferiores, componentes de la unidad nacional. Un reparto, además, que al concretarse en los Estatutos, por vías paccionadas, vincula en todo caso con especial vigor tanto al Estado como a las propias Comunidades Autónomas.

Claro que, de haberse institucionalizado la potestad normativa de los Parlamentos regionales como algo exclusivamente administrativo o reglamentario, el control sobre ella no estaría, como hoy, reservado, a la postre, al Tribunal Constitucional, sino que podría ser ejercido por cualquier Tribunal de Justicia y en particular por la Jurisdicción contencioso-administrativa. Pero no creo que ello pueda representar merma real alguna del efectivo alcance político de la autonomía regional (o nacionalitaria), habida cuenta de que, a diferencia de lo que ocurre de ordinario en los Estados Federales, en el Derecho español el Poder Judicial es uno e independiente 
para toda la Nación, radicado en el Estado no más ni menos que el Tribunal Constitucional. Además, muy bien podría haberse potenciado al respecto la función jurisdiccional de los Tribunales Superiores de Justicia en esa labor de control jurídico de las normas autonómicas, con alto beneficio, por cierto, para los ciudadanos -que tendrían más próxima la Justicia - para el mismo Tribunal Constitucional - que quedaría descargado de una buena parte de su actual sobrecarga funcional - y para la misma imagen de la autonomía regional, que vería resolver en su propio ámbito territorial los «juicios» contra sus normas (sin perjuicio de los supuestos en que debiera quedar abierta la vía de la casación o de la revisión extraordinaria por el Tribunal Supremo).

Por lo demás, por sí sólo el reconocimiento de la verdadera naturaleza reglamentaria de las hoy denominadas leyes autonómicas - para las que bien encajaría el nombre de ordenanzas regionales, que llegó a ser propuesto en algún momento de la elaboración parlamentaria de nuestra Constitución-, no requeriría cambios sustanciales en la composición de Asambleas autonómicas, ni en su procedimiento de elaboración y aprobación de sus productos normativos. Ciertamente denominaciones como Cortes, Parlamentos, pudieran resultar un tanto pretenciosas o excesivas, al no disponerse de facultades propiamente legislativas por vía estatutaria. Pero no debe olvidarse que la realidad de las cosas no cambia porque se hagan concesiones puramente terminológicas o verbalistas. Si existen hoy razones de apegos o resonancias históricas para acoger aquellas denominaciones, podrían seguirse aceptando sin especiales dificultades. Lo importante, en cualquier caso, sería mantener y aun potenciar su carácter representativo, del modo que mejor se reflejara la verdadera naturaleza de cada comunidad regional o nacionalista, y ello como fundamento de la amplitud de sus competencias normativas y de la importancia de las reservas materiales al respecto determinables por los Estatutos.

Lo que es, sin embargo, indudable es que el tratamiento que estamos proponiendo para la función normativa de las Asambleas de las Comunidades Autónomas, a fuer de expresar con más autenticidad la realidad de las cosas, llevaría a que las Comunidades Autónomas y el Estado tuvieran una más clara conciencia de su real identidad y aceptasen mejor el colocarse adecuadamente en sus respectivos lugares constitucionales, evitándose quizá la excesiva conflictividad que viene presenciándose entre unas y otro, $\mathrm{y}$ 
acabando con esa actitud poco provechosa de tantos próceres autonómicos que tienden a llevar a las Comunidades Autónomas a un imprudente mimetismo con el Estado, en los más diversos órdenes. Lejos de las preocupaciones, inútiles aquí, derivadas del principio de separación de los Poderes Legislativo y Ejecutivo, propios del Estado, cabria aplicar fórmulas institucionales más apropiadas a las necesidades y cometidos específicos de las Comunidades Autónomas.

Estas rápidas reflexiones sobre las consecuencias de que el reparto competencial normativo entre Estado y Comunidades Autónomas no es tan sólo ni principalmente horizontal - con ser éste importante-, sino también y muy destacadamente vertical, no deben llevar, finalmente, a situar las normas autonómicas en el mismo nivel y grado que las locales, dictadas por las Corporaciones locales, por grandes que sean sus similitudes.

Aunque la garantía institucional de la Administración Local, constitucionalmente establecida, puede exigir ciertas cotas de potestad reglamentaria, la determinación y regulación de ésta siempre será cometido unilateral del Estado y, en su caso, también de las Comunidades Autónomas, complementariamente. Las normas estatales y autonómicas deben respetar el ámbito que pueda considerarse constitucionalmente exigido para la autonomía normativa local, en lo que encontramos semejanza no pequeña con la analizada reserva competencial atribuible a las Comunidades Autónomas; pero esas normas locales, dentro de esas exigencias constitucionales, están sometidas a la libre disponibilidad unilateral del Estado y, en su caso, Comunidades Autónomas, marcándose con ello una sustancial diferencia con respecto a la firmeza de que se beneficia la reserva competencial en favor de las Comunidades Autónomas una vez que se encuentre establecida en unos Estatutos de Autonomía sustraidos a la unilateral disponibilidad del poder legislativo estatal. El alcance material, además, de las normas autonómicas será notablemente más extenso y permitirá una más intensa ordenación jurídica por comparación con las normas locales.

\section{OBSERVACIONES SOBRE LA POTESTAD REGLAMENTARIA DE LAS COMUNIDADES AUTONOMAS}

Volviendo a los planteamientos, no sólo formales, sino nominalistas que presiden actualmente el tratamiento de la potestad 
normativa de las Comunidades Autónonas, conviene hacer alguna reflexión complementaria sobre la regulación de la potestad reglamentaria autonómica en cuanto distinta de la potestad legislativa autonómica. No sin antes indicar que perfectamente podría operarse una distribución de competencias normativas entre Asamblea y Consejo de Gobierno, aunque las dos se considerasen de naturaleza administrativa o reglamentaria, en los términos explicados; distribución que, por cierto, debería traer como resultado una mayor participación efectiva de la Asamblea en dicha función normativa.

Recordemos, ante todo, que como regla los Estatutos atribuyen el ejercicio de la potestad legislativa a las Asambleas y el de la reglamentaria a los Gobiernos. Esa regla tiene, no obstante, dos excepciones: los Estatutos asturiano y riojano asignan, en efecto, respectivamente a la Junta General del Principado y a la Diputación General, como ya dijimos, el ejercicio de la potestad reglamentaria en las materias en que sólo corresponde a la Comunidad Autónoma la ejecución de la legislación estatal. Hay, por cierto, una diferencia no desdeñable entre el modo en que se reconoce esa potestad reglamentaria en uno y otro Estatuto. En el asturiano, a consecuencia de una alteración introducida en las Cortes Generales, esa competencia reglamentaria de la Junta General sólo alcanzará a la "organización de los servicios», correspondiendo la competencia reglamentaria propiamente ejecutiva - «jurídica»- en todo caso al Estado, en virtud de lo dispuesto en el artículo 12 del Estatuto y de acuerdo con la interpretación material que se ha venido haciendo del término legislación cuando es empleado en el artículo 149.1, según ya recordamos en su momento. En el riojano, en cambio - a semejanza de lo que preveía el Proyecto del asturiano, elaborado en Asturias-, no existe tal restricción ni tal reserva al Estado: según el artículo 10 del Estatuto de La Rioja el Estado podrá dictar normas reglamentarias en dichas materias de ejecución autonómica, pero no deberá necesariamente hacerlo, y el artículo 17.1.b) contiene una amplia redacción relativa, en general, al «desarrollo de la legislación del Estado». El Estatuto riojano logró pasar por las Cortes Generales sin sufrir el recorte que se impuso al de Asturias cuando sobrevolaba en el Parlamento nacional el llamado espíritu de la LOAPA y pesaba ya también la interpretación del Tribunal Constitucional acerca del término «legislación» empleado en el artículo 149.1.

Estas dos excepciones que, aunque en pequeña medida, reçuer- 
dan el sistema italiano, están manifestando una preocupación que ha podido ser más sensible precisamente en Comunidades Autónomas uniprovinciales, en las que las nuevas instituciones autonómicas habrian de sustituir a unas Corporaciones provinciales con una larga tradición de autoadministración: la preocupación cabalmente de que el mimetismo institucional con respecto a la organización del Estado, combinado con la real limitación de la competencia formalmente legislativa autonómica, pudiera traer consigo, paradójicamente, una reducción de las posibilidades de intervención y decisión del máximo órgano representativo de las Regiones y Nacionalidades en la función normativa reconocida a las entidades territoriales correspondientes. Ya BASSOLS COMA ha destacado con acierto el efecto además de "reserva reglamentaria» a los Gobiernos autonómicos, que puede derivarse del formalista sistema adoptado (24). Y es que, en verdad, en las materias en que la Comunidad Autónoma carezca de competencias legislativas -que por encima de expresiones estatutarias, siempre serán complementarias o de desarrollo, aunque de diverso alcance-, se corre el riesgo de que las Asambleas no tengan más facultades que la de control sobre el Ejecutivo autonómico, el cual, en ejercicio de su potestad reglamentaria, sustraerá a aquéllas toda posibilidad de intervención directamente ordenadora. Y téngase en cuenta que no se trata de materias despreciables, sino de sectores de la relevancia de la protección del medio ambiente, denominaciones de origen, comercio interior y defensa del consumidor, industria y -donde se ha reconocido una autonomía plena- asuntos penitenciarios, laborales, propiedad intelectual e industrial, etc. Puede comprobarse acudiendo, por ejemplo, al artículo 28 del Estatuto de Castilla-León, al 12 del del Principado de Asturias, o al 36.2 del de Aragón, en cuanto al primer grupo de ejemplos extraídos de Estatutos de Comunidades Autónomas de autonomía lenta, y al artículo 12 del Estatuto catalán o al 12, también, del vasco, por lo que se refiere a los ejemplos relativos a Comunidades de autonomía plena. Incluso en materia de Administración Local, tan importante para todas las Comunidades Autónomas, pero en la que el artículo 148.1.2. ${ }^{\mathrm{a}}$ no

(24) Cfr. B.sssols Com.A. M.: Las diversas manifestaciones..., cit.. supra, en nota (11), y "Organizacion institucional $y$ regimen juridico de las Comunidades Autonomas", en Organizacion territorial del Estado (Comunidades Autonomas), vol. I. IEF. Madrid. 1984, especialmente p. 196. 
autoriza asignar estatutariamente competencias que rebasen lo administrativo a las Comunidades Autónomas de segundo grado, en su primera fase autonómica, resultaría que, a pesar de lo que suelen decir con cierta dosis de ambigüedad los Estatutos, sólo los Consejos de Gobierno podrían dar normas -reglamentarias, administrativas, las únicas posibles- en esa materia, sin que las Asambleas legislativas puedan dar norma alguna, ya que la legislación formal seguiria siendo competencia reservada al Estado en las citadas Comunidades de autonomía no plena.

Parece justificado, en consecuencia, propiciar, no sólo la admisión de una potestad reglamentaria propiamente «jurídica» en favor de las Comunidades Autónomas en materias en que la Constitución sólo reserva al Estado la legislación, sino también extender la solución apuntada en los Estatutos asturiano y riojano, de modo que esa potestad puedan ejercerla las Asambleas.

\section{ALGUNAS REFERENCIAS DE DERECHO COMPARADO: ITALIA, BELGICA Y ALEMANIA}

Nos ha parecido útil establecer algunas relaciones de comparación entre las características de la función normativa de las Comunidades Autónomas españolas y la atribuida a las Entidades de tipo territorial análogo en esos tres modelos europeos diferentes de organización del Estado. No pretendemos hacer ahora un análisis en profundidad de esta cuestión, que excedería con mucho las razonables limitaciones de esta Comunicación, sino simplemente aludir a los rasgos más sobresalientes que permitan una aproximación a lo que podría ser una valoración comparativa de los distintos sistemas de vertebración del Poder público en su organización territorial.

a) La Constitución italiana, en primer término, en el artículo 117 habilita a las Regiones para dictar normas legislativas dentro de los límites de los principios fundamentales establecidos en las leyes del Estado, siempre que dichas normas no se opongan a los intereses nacionales y a los de las otras Regiones, y respecto de un listado de materias que el mismo precepto precisa y que pueden ampliarse mediante "leyes constitucionales». El artículo 121 atribuye al denominado Consejo regional el ejercicio de «las potestades legislativas y reglamentarias atribuidas a la Región»: el mismo artículo 117 antes citado, además de atribuir a la Región potestad 
legislativa en los términos indicados, señala que «las leyes de la República podrán atribuir a la Región el poder de dictar normas para su actuación», que - parece- tendrían carácter reglamentario.

Junto a otros muchos ilustres comentaristas de la potestad legislativa y reglamentaria regional, Alessandro CATELANI dedicaba al tema un buen trabajo en mayo de 1983, en Il Foro Amministrativo (25), del que entresacaré algunas afirmaciones que me parecen especialmente reveladoras de la semejanza con que se plantea la cuestión central de esta Comunicación en el Derecho italiano y en el Derecho español, aunque diversos autores entre nosotros adviertan sobre las diferencias entre nuestro sistema y el regional italiano.

Subraya, ante todo, CATELANI - como ya lo habian hecho antes de él otros autores- que «las leyes regionales, aun siendo leyes, no son expresiones de soberanía (...), ya que su posición es del todo particular (...), una posición que acerca al acto legislativo de las Regiones al reglamento que ellas mismas pueden dictar» (26). $\mathrm{Y}$ antes de esas reveladoras afirmaciones, escribe igualmente que: «Las leyes regionales constituyen actos formalmente legislativos, pero su naturaleza es bien distinta de la de las leyes estatales, por cuanto las leyes regionales, a diferencia de las estatales, son expresión de autonomía, y no de soberanía, la cual solamente corresponde al ordenamiento estatal en su conjunto" (27), dado que «como todos los demás entes públicos, las Regiones no constituyen ordenamientos originarios y soberanos, sino meramente derivados» (28). "La potestad legislativa regional no llega a poder disciplinar cualquier aspecto de la vida social, sin otros límites que los sancionados en la Constitución, como sucede con la ley ordinaria del Estado" (29). La potestad legislativa de las Régiones es también definida, en el ámbito de las materias de su competencia, por una institucional subordinación a los poderes soberanos del legislador estatal, ya que la ley estatal es portadora del interés del ordenamiento en su unidad y debe subordinarse a ella el interés de las Regiones. La subordinación implica superposición de las dos fuen-

(25) Cfr. CATElani, A.: "I regolamenti amministrativi delle Regioni", Il Foro Amministrativo, núm. 5, 1983, pp. 246-266.

(26) Ibidem, p. 251.

(27) Ibidem, pp. 248-249.

(28) Ibidem, p. 247.

(29) Ibidem, p. 249. 
tes normativas, pero no en pie de igualdad, sino como prevalencia de la fuente normativa estatal sobre la regional. «Junto a la delimitación en razón del territorio y de la materia, es, pues, además connatural a la potestad legislativa regional una institucional subordinación a la ley ordinaria estatal - y no ya solamente a la Constitución» (30). «Estamos ante una elección estrictamente coherente con el planteamiento que nuestra Constitución ha efectuado - añade el autor que venimos citando- acerca de la indivisibilidad y unidad de nuestro ordenamiento".

Es realmente asombrosa la similitud del razonamiento que nos ofrece este autor con el que es posible y aun obligado hacer a la vista de los datos de la Constitución española.

CATELANI añade, con razón, que «la subordinación de las leyes regionales respecto a la estatal, que se manifiesta bajo múltiples aspectos (...), encuentra correspondencia en su adherencia a la regulación concreta que es típica de la norma reglamentaria. Es decir, la ley regional, en esta disciplina, se coloca, con sus normas, en la misma posición jurídica del reglamento, efectuando una regulación directa e inmediata de los varios supuestos, que es estrechamente afin a la reglamentaria» (31).

Y, a semejanza de lo que venimos observando en España, también en Italia «la subordinación de la ley regional respecto a la estatal, impulsa a la primera a ocupar el campo que habitualmente compete a la potestad reglamentaria, que pasa a ser de la competencia de las leyes regionales. El espacio que se presta para una regulación primaria (dentro del marco establecido por el Estado) por la potestad reglamentaria, viene ocupado por la ley regional a través de normas que indudablemente están bastante más cerca del reglamento que de lo que pueda estarlo la ley del Estado respecto a los reglamentos emanados del Estado o de otros entes públicos» (32). En fin, «entre leyes y reglamentos regionales hay una distinción de naturaleza formal, pero que como tal no mira a la esencia de la norma y no es idónea para caracterizar su contenido, por cuanto el valor normativo de las leyes y de los reglamentos regionales es unitario, conteniendo ambos normas jurídicas de análoga estructura» (33).

(30) Ibidem, p. 250.

(31) Ibidem, p. 253.

(32) Ibidem, p. 253.

(33) Ibidem, p. 254. 
En la práctica italiana, al no utilizarse un criterio de distribución de funciones basado en la distinción formal entre lo legislativo y lo ejecutivo (incluyendo lo reglamentario), se admite que en ejercicio de competencias de ejecución las normas necesarias se formalicen como leyes regionales. Aunque los mismos Consejos regionales legisladores dicten después, cuando es necesario, reglamentos ejecutivos más pormenorizados, justificándose el ejercicio de esta potestad reglamentaria en una exigencia democrática (34), conducente esencialmente a atribuir a los Consejos funciones de administración activa (35), dada su competencia «bien diversa de la que es propia del Parlamento de la República, que, al menos como criterio general, se limita al ejercicio de la función legislativa». "El Consejo regional, a diferencia del Parlamento de la República, no ejerce una actividad legislativa tan intensa que se vea impedida integramente la posibilidad de intervenir directamente en la gestión de los asuntos regionales. La simplicidad de la organización regional, en comparación con la ciel Estado, permite al Consejo regional ejercer una actividad administrativa de notable alcance, hasta el punto de poder coadyuvar con la Junta en el ejercicio de su actividad" (36). Y subraya CATELANI, en fin, que aunque el poder reglamentario compete típicamente a los órganos ejecutivos, nada impide que sea ejercitado por órganos legislativos si no hay reserva en favor de la autoridad administrativa que esté constitucionalmente garantizada (37).

Las referencias que acabamos de recoger permiten afirmar la notable similitud que media entre la potestad normativa de las Regiones italianas y la de las Comunidades Autónomas españolas, sin perjuicio de posibles diferencias en cuanto a su aplicación a ámbitos materiales específicos y dejando a salvo la realidad de que nuestros Estatutos autonómicos, por lo general, han atribuido el ejercicio de toda la potestad reglamentaria, no a las Asambleas

(34) Ibidem, p. 257.

(35) Ibidem, p. 258.

(36) Ibidem, loc. cit

(37) Ibidem, loc. cit. $\mathrm{Y}$ en la p. 257 dice también que «la atribución de poderes reglamentarios al Consejo regional presenta la ventaja de devolver tal poder a un órgano formado democráticamente, mediante elecciones libres, con lo que todos los poderes normativos de las Regiones vienen asi a ser expresion de la voluntad popular, de la mayoria que se forma dentro de la colectividad regional". Aunque cabria objetar que tambien la Junta puede expresar esa mayoria, no puede negarse la justificación del criterio expuesto en la mayor participación de la representación colectiva que se produce en el seno del Consejo regional. 
-equivalentes a los Consejos regionales italianos-, sino a los Consejos de Gobierno -equivalentes de las Juntas italianas.

$\mathrm{Y}$ es que, desde el punto de vista constitucional más fundamental, tanto el orden jurídico-político italiano como el español, se basan en la unidad del Estado y del ordenamiento, en la unidad de la soberanía. Y si ésta, contra lo afirmado quizá en otro sentido algo más general por el mismo CATELANI, reside no en el Parlamento nacional, sino en el pueblo de la Nación (art. 1.2 CE), con la consecuencia del carácter limitado también de las competencias del Legislativo nacional, no es menos cierto que a éste y sólo a éste compete la salvaguarda de la unidad del ordenamiento jurídico nacional en su integridad.

Siguiendo pautas sentadas ya por otros autores -entre los que cabe destacar, por su autoridad, Guido ZANOBINI-, Livio PALADÍN señaló ya hace muchos años la sustancial analogía entre las leyes regionales y los reglamentos autónomos de los entes locales (38), así como la existencia de un principio general de supremacía de las leyes estatales respecto de las leyes de las Regiones (39). Como acertadamente explica, a diferencia de lo que ocurre en los Estados federales, el sistema de subdivisión de las competencias entre legislador central y legisladores locales, comporta que el legislador regional se inserta en un preexistente sistema de normas recíprocamente armonizantes, diferenciándolo solamente en los detalles y sin sustituir jamás integramente a la ley estatal en la regulación de la «materia legislativa». El legislador central conserva el poder exclusivo de establecer, en diversos planos, las líneas esenciales de todo el sistema. Los derechos regionales no pueden, en ningún caso, concebirse como un complejo de normas de proveniencia exclusivamente local (regional), sino que presupone una estable y necesaria trabazón entre normas estatales y locales. No hay, en suma, pluralidad de sistemas normativos dotados de propios principios, lógicamente independientes, que no se resuelvan en una mera especificación de las directrices de un sistema estatal unitario.

Por el contrario, en un Estado federal la legislación central carece, por definición, de capacidad de suprimir la preexistente

(38) Cfr. PAladin, L.: La potestá legislativa regionale, CEDAM, Padova, 1958, página 246 y ss., y en particular pp. 254 y ss. y 268.

(39) Ibidem, p. 254. 
pluralidad de sistemas normativos con entidad propia, los cuales vienen reducidos a unidad tan sólo en aquellos sectores específicamente enumerados en la Constitución. La diferencia se expresa dogmáticamente, según la tradicional concepción normativa del Derecho, con el axioma de que el Estado llamado regional posee en todo caso un ordenamiento unitario, caracterizado en su vértice por unos principios comunes, y no reconoce, por tanto, reserva alguna de ley regional que cubra enteros sectores del ordenamiento; mientras que el Estado federal se compone de una multiplicidad de ordenamientos, cada uno de los cuales se rige por principios propios, que encuentran en la legislación estatal un límite particular y eventual, pero no general ni necesario. La diferencia, por ello, entre Estado federal y Estado unitario de base regional, no es meramente cuantitativa, sino cualitativa (40). El Estado regional no es una figura intermedia entre Estado unitario y federal, sino una forma del Estado unitario (41).

b) El caso del ordenamiento belga presenta bastantes más peculiaridades, en las que, desde luego, no vamos ahora a entrar a fondo, limitándonos a señalar algunas de sus características más sobresalientes, que pueden marcar precisamente puntos de más destacable diferencia con respecto al perfil propio de la autonomía normativa de las Comunidades Autónomas españolas o de las Regiones italianas.

Como se sabe, Bélgica, erigida en nuevo Estado independiente en 1830 , conforme a la Constitución aprobada en el año 1831, es durante años uno de los ejemplos europeos más claros de Estado unitario, aun con una importante descentralización local, especialmente a nivel municipal. El lema del Estado - que por contraste alude a la preocupación central de los hombres que le dieron inicialmente vida- es precisamente el de L'union fait la force.

Desde el período entreguerras comienza a manifestarse,sin embargo, un creciente movimiento reivindicativo flamenco, que

(40) Ibidem. p. 269 y ss.

(41) Ibidem, pp. 271-272. En contra entre nosotros FerRando Badia, J.: Formas de Estado desde la perspectiva del Estado regional, IEP, Madrid, 1965, quien, salvo error de nuestra parte, no utilizo entonces la obra de PALADIN que hemos citado, a pesar de la importancia central precisamente de su reflexion sobre la potestad legislativa regional.

No podemos compartir posiciones como la de GonZález ENCINAR, J. J., en El Estado Unitario-Federal, Tecnos, Madrid, 1985, que niegan la posibilidad de contraponer actualmente las dos categorias. 
trata de replantear progresivamente las bases del orden cultural, económico y político asentado en el país y consolidado bajo el nuevo Estado unitario durante el siglo XIX. Ese movimiento tomará nuevo impulso en la década de los cincuenta y muy especialmente en la de los sesenta, traduciéndose en importantes reformas constitucionales a partir de 1970 , tendentes a una redistribución del Poder político bajo esquemas más próximos a lo federal que a lo regional o meramente autonómico.

La comprensión de las nuevas instituciones requiere saber previamente que Bélgica se compone sustancialmente de dos partes territoriales bastante netamente diferenciadas: un norte, de cultura flamenca o neerlandesa - las dos Provincias de Flandes, la de Amberes, el Limburgo y la mitad norte de la Provincia de Brabantey un sur, de cultura francófona, más extenso territorialmente, que es la Walonia y abarca las Provincias de Hainaut, Namur, Lieja, Luxemburgo y el sur del Brabante. Una línea horizontal que pasa pocos kilómetros al sur de Bruselas divide las dos Regiones naturales y sirve de encuentro a dos vanguardias de las grandes culturas germánica y latina que componen la centroeuropa. Bruselas, en efecto, la única aglomeración urbana realmente importante y capital del Estado - además de centro destacable de organismos europeos e internacionales - queda situada geográficamente en zona flamenca, aunque la mayoría de sus habitantes son francófonos. Hay, además, una pequeña parte del país, al este, en la Provincia de Lieja, que es de lengua y cultura alemana. Por lo demás, mientras el Norte tiene las ciudades más tradicionalmente comerciales y con importantes puertos marítimos, habiendo logrado un desarrollo industrial más reciente y moderno, lc que le permite una actual prosperidad más destacada, el Sur es la zona carbonífera y de la siderurgia, además de compartir con el Norte la riqueza agrícola y ganadera. En el Norte hay una mayoría política socialcristiana, y en el Sur una mayoría socialista.

En esas condiciones, el país vive unido merced a un esfuerzo continuado de equilibrio, a veces difícil.

En la reforma constitucional de 1970 se introduce un artículo 107 quater en el texto constitucional, que establece en Bélgica tres Regiones: la walona, la flamenca y la de Bruxelas. Una ley de mayoría especial habría de crear sus órganos compuestos por mandatarios elegidos y con competencia para regular las materias que ella deter- 
minaría, a excepción del empleo de lenguas y de las materias de competencia de las Comunidades culturales.

Por otra parte, se han creado también tres Comunidades culturales autónomas: la francesa, la flamenca y la alemana (arts. 59 bis y 59 ter), cada una con un Consejo - de elección popular- y un Ejecutivo, 'cuya composición y funcionamiento corresponde fijar a la Ley - siempre una Ley de mayoría especial- Expresamente se prevé en la Constitución para estas Comunidades -ya desde la reforma de 1970 - que los Consejos podrán regular por decreto una serie de materias que se determinan en el artículo 59 bis, $\$ .2$. Esos decretos -expresión no empleada en Derecho belga para los actos y disposiciones del Gobierno estatal, que reciben allí el nombre de arrêtes royales- tienen, según el $\$ .4$ del mismo artículo constitucional, fuerza de Ley. $\mathrm{Y}$ es de resaltar especialmente que en cuanto a la regulación del empleo de las lenguas, se dice expresamente que le corresponde por decreto a los Consejos de las Comunidades respectivas con exclusión del legislador ( $\mathrm{y}$ tanto para las materias administrativas como para la enseñanza en establecimientos creados, subvencionados o reconocidos por los Poderes públicos, como en las relaciones laborales y en cuanto a los actos y documentos de las empresas exigidos por la Ley y los reglamentos). Esa exclusión de la Ley de un campo material, de un modo tan expreso y completo, aunque ciertamente luego se dice que es la Ley quien determina las medidas para prevenir toda discriminación por razones ideológicas y filológicas, constituye un elemento a considerar como posible punto de importante diferenciación con respecto a las características y naturaleza de las leyes autonómicas españolas que, como hemos explicado, nunca tienen un tal posible carácter primario.

Tiene, en toda esta materia, importancia destacable la Ley especial de reformas institucionales, de 8 de agosto de 1980, que regula las instituciones comunitarias y regionales - la Comunidad flamenca y la Región flamenca se unen en unas instituciones comunes y siguen con instituciones separadas de la Comunidad francófona y la Región walona-. El artículo 6 viene a determinar las materias de competencia de las Regiones, concretando en cada una su alcance y sus límites, muy pormenorizadamente. No nos es posible aquí entrar en un análisis completo del cuadro íntegro de distribución competencial organizado. Ni siquiera vale la pena que intentemos una síntesis, que resultaría de todos modos precipitada 
e insuficiente, si no queremos alargar esta Comunicación ya mucho más.

También los Consejos -Asambleas- de las Regiones pueden dictar decretos con fuerza de Ley en las materias de su competencia. Y esos decretos, dentro de los límites competenciales, respectivamente, de las Comunidades o de las Regiones, según actúen como órganos de unas $u$ otras, pueden erigir en infracción las infracciones a sus disposiciones y establecer penas que las castiguen, de acuerdo con el Código Penal, con excepción de las penas criminales fijadas en el artículo 7 de dicho Código (art. 11 de la Ley especial).

No hay en las reservas competenciales en favor de la Ley, ninguna tan amplia y general como las que podemos encontrar en el Derecho español o en el Derecho italiano.

El sistema belga, en fin, dentro de una complejidad ciertamente considerable, parece reconocer, pues, la posibilidad de decretos autonómicos con fuerza de Ley de los Consejos correspondientes, democráticamente elegidos, que implanten normas verdaderamente primarias del ordenamiento, sólo supeditadas a la Constitución, sin que leyes del Estado puedan alterarlas con sus principios o bases. La cuestión requeriría un examen y una exposición más extensos, pero baste con lo indicado para subrayar esta importante diferencia con el sistema español.

Ciertamente, parece claro que pervive en Bélgica una soberanía única, y que, a la postre, toda la ordenación autonómica es obra directa de la Ley estatal, en cumplimiento de preceptos constitucionales muy generales. Lo cual permite seguir pensando que Bélgica es aún un Estado unitario, a pesar de todo. Pero allí sí que cabe hablar de una efectiva aproximación a fórmulas federales y de un cierto proceso de federalización. Expresión relevante de ello puede ser, precisamente, la regulación constitucional, a partir de 1970, de las leyes de mayoría cualificada, necesarias para alterar las divisiones y estructuras territoriales y las Regiones lingüísticas o las Comunidades culturales. Se trata de unas leyes que, para su aprobación requieren mayoría de votos en cada grupo lingüístico de cada una de las Cámaras del Parlamento, además de exigirse la condición de que se encuentren reunidos en la correspondiente votación la mayoría de los miembros de cada grupo, y que el total de votos positivos emitidos en los dos grupos lingüísticos - flamenco y francófono- llegue a alcanzar los dos tercios de los 
sufragios emitidos (art. 1, art. 107 quater, ambos de la Constitución, tras la reforma de 24 de diciembre de 1970). Qué duda cabe de que se está reconociendo ahí una cierta estructura compartida de la comunidad nacional representada en el Parlamento. Con todo, para la revisión de la Constitución - regulada en el art. 131sigue sin introducirse referencia alguna a la estructura bicultural o bicomunitaria de la Nación, con lo que parece que, en último extremo, se mantiene la unidad de soberanía y la unidad del Estado.

Por otra parte, la misma adopción del término decreto para las disposiciones regionales y comunitarias con fuerza de Ley, así como los de Consejos - para los órganos titulares de la potestad correspondiente- o la de Regiones y Comunidades, parece querer traducir una voluntad del constituyente de mantener el carácter unitario del Estado y no reconocer a las instituciones autonómicas signos propios de los Estados miembros de un Estado federal. Aunque, por cierto, no deja de ser revelador que en la práctica el decreto regional o comunitario belga pueda tener una eficacia ordenadora más realmente legislativa en ciertos puntos que la que pueda reconocerse en las leyes regionales italianas o en las autonómicas españolas. De ahí que, como señalamos al principio de este trabajo, sea necesario siempre examinar lo que haya en realidad tras los nombres, para hacerse cargo de la entidad verdadera del sistema y de las instituciones.

Señalemos, en fin, que el artículo 19 de la Ley especial de reformas institucionales de 1980, fija a los decretos el límite de las reservas a la ley contenidas en la Constitución. Estas reservas son numerosas, aunque ciertamente no haya ninguna de la generalidad implicada en la reserva de ley sobre el derecho de propiedad o la libertad de empresa, efectuadas por el artículo 53.1 de la Constitución española. Ya hemos indicado de pasada, al referirnos a la competencia comunitaria sobre el uso de las lenguas que, aunque la Constitución dice expresamente que el decreto puede regular dicho uso con exclusión de la legislación estatal, se añade después que, sin embargo, la' ley puede establecer las medidas que se estimen necesarias para garantizar que no se produzcan discriminaciones, lo cual es ya un reconocimiento de que entre la Constitución y el poder «decretal» pueda interponerse, en la materia, un mandato del Legislador nacional.

Por lo demás, las reformas no han tocado en Bélgica el Poder judicial, que sigue siendo exclusivamente estatal. 
Las competencias regionales y comunitarias, aun admitiéndose unos poderes implícitos, en la medida en que estén estrechamente vinculados con ellas, siguen siendo competencias de atribución, permaneciendo en el Estado las competencias residuales.

Subsisten, en conclusión, por lo esencial, los caracteres de los Estados unitarios, aunque el poder «decretal» autonómico pueda, en algún campo, ser auténtico poder legislativo, como hemos expuesto (42).

c) Por lo que se refiere, finalmente, al Derecho público de la República Federal de Alemania, destacaremos como sustanciales diferencias con respecto al Derecho español, las siguientes:

Según el artículo 70.1 de la Ley Fundamental de Bonn, los Länder tienen la facultad legislativa en cuanto dicha Ley Fundamental no la confiera a la Federación. Es, pues, la competencia de la Federación la que aquí tiene naturaleza de competencia de atribución, correspondiendo a los Länder la residual.

La potestad legislativa se distribuye, sin embargo, entre Bund y Länder, de modo que aquél retiene competencia exclusiva en una serie de materias importantes que fija el artículo 73 , y se reconoce un muy extenso campo material, luego, de legislación concurrente, en el cual los Länder tienen la facultad de legislar en tanto y en cuanto no lo haga el Bund (art. 72.1). Ahora bien, éste no puede ejercer esa facultad, según el artículo 72.2, sino cuando exista la necesidad de hacerlo porque un asunto no pudiera ser satisfactoriamente regulado por la legislación de los Länder, o la regulación por ley de un Land pudiera afectar a los intereses de otros Länder y los intereses generales o, en fin, cuando lo requiera el mantenimiento de la unidad jurídica o económica, especialmente el mantenimiento de condiciones de vida uniformes más allá del territorio de un Estado.

La verdad es que la amplitud de las materias de legislación concurrente establecidas en el artículo 74, y de modo análogo en otros preceptos constitucionales, lleva a pensar que raro debe ser el campo de la realidad en el que no pueda legislar el Bund en las condiciones fijadas por el artículo 72 citado. Con lo que podríamos afirmar que las leyes de los Länder, por estar, en realidad, subor-

(42) Vid. DELPEREE, F.: L'autonomie locale en Belgique, au Luxembourg et aux PaysBas, Cabay, Louvain-La-Neuve, 1978, y Droit constitutionnel (t. I: Les donnés constitutionnelles), F. Larcier, Bruselas, 1980. 
dinadas a las del Bund, vendrían a merecer una calificación como la que hemos hecho con respecto a las leyes autonómicas españolas o las regionales italianas.

Sin embargo, debe subrayarse el carácter excepcional con que se contempla el ejercicio de la potestad legislativa del Bund en las materias de legislación concurrente, que requiere poder demostrar, en su caso, ante el Tribunal Constitucional, la concurrencia de alguna de las causas referenciadas, con cuyo concurso el artículo 72.2 abre las puertas a dicha potestad. Esas intervenciones legislativas del Bund se asemejan por ello a las que nuestra Constitución prevé en el artículo 150.3 con carácter extraordinario, aunque no lleguen a ser tan excepcionales como parece concebirse la ley armonizadora en nuestro Derecho (precisamente porque, como aclaró la Sentencia sobre la LOAPA, nuestro ordenamiento establece otros mecanismos de legislación básica normal y ordinaria). De modo que en el sistema alemán, como corresponde a un sistema federal, las leyes de los Estados miembros siguen teniendo un carácter primario en sectores aún importantes de la realidad, aunque haya que matizar ese carácter por su sumisión a la posible intervención legislativa estatal por las razones especiales indicadas. La diferencia, ciertamente, podrá decirse que en la práctica no será muy grande. Pero no puede pasarse por alto, porque es, sin duda, muy relevante.

Lo expuesto debe, además, integrarse en el marco constitucional general de la Constitución alemana, indudablemente federal. Los Länder con el Bund tienen consideración de partes constituyentes (Título II de la Ley Fundamental, art. 20 y preámbulo) y es inadmisible toda modificación de la Ley Fundamental que afecte a la diṿisión de la Federación en Estados (art. 79.3). Consecuencia de ello es, asimismo, la importancia del Bundesrat o Consejo Federal, como Cámara Alta formada por miembros de los Gobiernos de los Länder, a través de la cual, como dice el artículo 50, éstos cooperan en la legislación y administración de la Federación.

No puede pasarse por alto, de otra parte, la amplitud de las materias sobre las cuales recae la legislación concurrente, y por tanto la legislación —en muchos casos primaria - de los Länder. Destacaré, por contraste con el ámbito de la competencia legislativa autonómica española, el Derecho civil y el Derecho penal, la organización y el procedimiento judicial, el derecho de asociación y reunión o el derecho laboral (vid. art. 74 de la Ley Funda- 
mental de Bonn), campos éstos que están totalmente excluidos de la actividad normativa "legislativa» de las Comunidades Autónomas, al menos en cuanto a sus competencias estatutarias constitucionalmente permitidas (43) (44).

\section{REFLEXIONES CRITICAS FINALES SOBRE LAS CONSECUENCIAS ESTRUCTURALES Y FUNCIONALES DE LA CARACTERIZACION FORMALMENTE LEGISLATIVA DE LAS ASAMBLEAS AUTONOMICAS POR RAZON DE SUS FUNCIONES}

Todo lo que está montado con falta de coherencia o de autenticidad puede acarrear consecuencias no deseables o no precisamente beneficiosas. Algo de esto puede estar ocurriendo con la implantación de las Comunidades Autónomas españolas.

La caracterización formalmente legislativa de la función normativa encomendada a las Asambleas y, por ello, de estas mismas, ha llevado a estructurar las instituciones de las Comunidades Autónomas sobre el patrón estatal de la separación de poderes y el régimen parlamentario de gobierno, lo cual trae consigo de modo generalizado y bastante uniforme, el montaje de una Administración de corte burocrático, alejada del modelo de autoadministración que podía ser deseable a esos niveles de Administración territorial, para que pudiera producirse una mayor participación de los representantes de los intereses generales de los administrados en la dirección de la gestión administrativa como un resultado beneficioso de la ruptura del anterior centralismo estatal.

Las minorias políticas representadas en las Asambleas Legislativas reducen su papel al de la clásica oposición parlamentaria, quedando fuera de toda intervención directa en las decisiones determinantes de la actividad administrativa autonómica, sin que, por otra parte, tengan mucho sobre lo que legislar.

Al aplicar a los Parlamentos autonómicos los mismos principios que al Parlamento nacional, surge todo un aparato administrativo parlamentario en cada Comunidad Autónoma, de dudosa

(43) Con la excepción ya señalada páginas atrás de los derechos civiles forales en los términos que precisa el articulo 149.1.8. ${ }^{\mathrm{a}}$

(44) Vid., no obstante, en SCHNEIDER, H. P.: "El Estado federal cooperativo", REP, número 12 , nueva época, p. 53 , la práctica reducción de la competencia legislativa sufrida por los Länder en proceso de indudable "unitarización» del sistema. 
justificación real, independiente de la Administración gubernativa autonómica (dependiente del correspondiente Consejo de Gobierno).

El sistema adoptado en muchas Comunidades de limitación del tiempo de sesiones y de retribución de los parlamentarios por dietas -en un intento de reducir posibles «excesos», siempre dentro del espíritu de la LOAPA-, además de manifestar una cierta mala conciencia del Estado ante el reconocimiento del carácter «legislativo» de los Parlamentos autonómicos, contribuye a su inoperancia.

No es de extrañar cierto sentimiento de frustración ante estos singulares Parlamentos y que traten de compensarse aprovechando al máximo sus competencias para el desarrollo de la legislación básica estatal, dictando cuantas leyes puedan, y leyes tan pormenorizadas como los clásicos reglamentos, congelando así, por cierto al rango de ley formal muchos preceptos que, de otro modo, tendrían mero valor reglamentario y podrían ser más fácilmente fiscalizados por los Tribunales.

De otra parte, la conciencia de la posesión de un poder «legislativo» impulsa una difusa conciencia autonómica en los líderes políticos, propicia a la permanente pugna con el Estado sobre el alcance de los respectivos poderes legislativos. Algo que así planteado resulta bastante estéril y que no rara vez alimenta la creencia de que uno y otro Poder público tienen, a la postre, la misma entidad.

Se ha caído, asimismo, en la más completa uniformidad en la regulación estatutaria de las Asambleas y de los demás órganos superiores de las Comunidades Autónomas, cerrando los ánimos a cualquier intento creativo de algo más original, que tratara de operar eventualmente un mejor ajustamiento de las realidades institucionales y las verdaderas necesidades e intereses del autogobierno regional en las diversas Regiones y Nacionalidades españolas. En otros lugares hemos hablado de la conveniencia de que las Asambleas de las Comunidades uniprovinciales recogieran en su composición la estructura intermunicipal de las ProvinciasComunidades Autónomas, y de que en algunas Comunidades pluriprovinciales, en las que las Provincias constituyen un fenómeno histórico, económico, social, cultural y administrativo fuertemente arraigado, las Asambleas pudieran reflejar la real estructura interprovincial de esas Regiones, con una representatividad popular 
que pasara por las representaciones de las Corporaciones provinciales. Ninguna norma hay en la Constitución que exija la representación popular directa en las Asambleas de las Comunidades Autónomas, ni siquiera aunque persista la configuración formalmente legislativa actual de su función. Pero qué duda cabe que esta nominalista conceptualización ha dado motivos para la implantación generalizada del sufragio directo en la elección de dichas Asambleas, sin más consideraciones.

Las dificultades de los administrados -e incluso de la oposición política interna - para oponerse en vía jurisdiccional a las normas autonómicas con rango de ley, en comparación con lo que ocurriría si se tratase de normas reconocidamente administrativas, no es la menor de las objeciones que el sistema suscita, y no vamos a insistir más en ello.

Es posible que el sistema instaurado sea ya irreversible. No lo creo así. No obstante, las consideraciones expuestas podrían servir en cualquier caso como una llamada al realismo, tendente a evitar que un deficiente modo de entender el alcance de la autonomía "política» de nuestras Regiones y Nacionalidades acabe por volverse en contra de la afirmación y ordenada expansión de esa misma autonomía, en armónica conjunción con la unidad y solidaridad de la Nación que la Constitución garantiza.

Debería potenciarse con claridad la función directiva y normativa de las Asambleas autonómicas, pero sin ambigüedades sobre la verdadera naturaleza subordinada a la única auténtica Ley, la del Estado, de cuantas normas sean producidas por ellas, sin merma de las reservas competenciales que deban establecerse en su favor, limitando las propias competencias estatales. 
REALA-1986, núm. 230. MARTINEZ LOPEZ-MUÑIZ, JOSE LUIS. NATURALEZA DE LA FUNCION ...

REALA-1986, núm. 230. MARTINEZ LOPEZ-MUÑIZ, JOSE LUIS. NATURALEZA DE LA FUNCION .. 